\title{
Dynamic Stabilization of DC Traction Systems Using a Supercapacitor-Based Active Stabilizer With Model Predictive Control
}

\author{
Farshid Naseri ${ }^{\circledR}$, Student Member, IEEE, Ebrahim Farjah ${ }^{\circledR}$, Member, IEEE, \\ Zahra Kazemi $^{\circledR}$, Student Member, IEEE, Erik Schaltz ${ }^{\circledR}$, Member, IEEE, \\ Teymoor Ghanbari $^{\circledR}$, and Jean-Luc Schanen, Senior Member, IEEE
}

\begin{abstract}
The increasing urbanization, population, and travel demand lead to a higher density of trains in subway or tramway lines, which weakens the energy-feeding dc substations of these city transportation means. Under such circumstances, voltage sags in the upstream ac grid, resistive voltage drops in dc feeders, and constant power load (CPL) nature of subway and tramway traction units can lead to momentous fluctuations in the dc-link voltage. To rectify this problem, a supercapacitor-based active stabilizer (SBAS) with a two-mode control strategy (TMCS) is proposed in this article. It is shown that the proposed SBAS exhibits the behavior of a varying capacitance at the bus side. This feature is used in conjunction with the proposed TMCS based on model predictive control (MPC) to improve the stability of the system and to mitigate the variations of the dc-link voltage. The effectiveness of the proposed method is demonstrated by simulation of a typical subway system as well as by a series of experiments on a scaled prototype. The results show that the dc-link voltage drop never exceeds $2 \%$ when the proposed SBAS is used. In addition, the real-time feasibility of the proposed MPC-based TMCS is demonstrated by real-time hardware-inthe-loop (HIL) experiments.

Index Terms-Constant power load (CPL), model predictive control (MPC), railway traction system, supercapacitor.
\end{abstract}

\section{INTRODUCTION}

C ITY transportation systems such as tramways and subways are normally supplied through passive rectifier substations connected to medium voltage (MV) distribution grids. The traction units of tramway or subway trains mostly include ac electric motors driven by variable frequency converters, which are commonly fed through 600-2000-V dc bus of the rectifier substations [1], [2]. As the density and power of the trains become more and more significant due to the increasing travel demand, the voltage fluctuations along the travel lines become a serious problem [3], [4]. In fact, due to the constant power load (CPL) nature of the closed-loop

Manuscript received August 23, 2019; revised November 29, 2019; accepted December 27, 2019. Date of publication January 6, 2020; date of current version March 20, 2020. (Corresponding author: Ebrahim Farjah.)

Farshid Naseri, Ebrahim Farjah, Zahra Kazemi, and Teymoor Ghanbari are with the School of Electrical and Computer Engineering, Shiraz University, Shiraz 71557-13876, Iran (e-mail: f.naseri@shirazu.ac.ir; farjah@shirazu.ac.ir; z.kazemi@shirazu.ac.ir; ghanbarih@shirazu.ac.ir).

Erik Schaltz is with the Department of Energy Technology, Aalborg University, 9220 Aalborg, Denmark (e-mail: esc@et.aau.dk).

Jean-Luc Schanen is with the Grenoble Electrical Engineering Laboratory (G2ELab),38000Grenoble,France(e-mail:jean-luc.schanen@grenoble-inp.fr). traction converters, the electric motor and conversion system exhibit negative incremental impedance behavior, which can intensify the level of the voltage drop on the bus side [5]. In addition, power quality issues such as voltage sag incidents on the upstream ac grid can also result in a substantial voltage drop on the dc bus of the weakened traction system. The voltage drop may even become worse with the unusual presence of two or more trains at the same location (for instance, due to an unexpected accident or traffic jam) [2]. In order to guarantee the stability of the system under such conditions, some limits are usually imposed on the level of voltage drop in traction substations. For instance, standard EN 50163 defines minimum long-term, dc-link voltage of $1000-\mathrm{V}$ dc for traction substations with a rated voltage of $1500-V$ dc. In addition, standard EN 50388 specifies that there must be a mechanism to adapt the power consumption of the train depending on the overhead contact line voltage under steady-state conditions. Although these standards mitigate the problem to some extent, the voltage drop still results in the degradation of train performance, e.g., the train will be forced to travel at a lower speed. A solution to this problem is to add new rectifier substations. However, the foregoing method has infrastructure laboriousness and very high costs. In addition, the destabilizing behavior of the CPLs cannot be diminished by the aforementioned approach. Another alternative is to use supplementary energy storage systems (ESSs) to improve the voltage profile [2], [6]-[15]. The latter solution has been studied in a number of works, which are briefly reviewed in the following.

In [2], a fixed energy storage substation based on the supercapacitor has been installed at the end of the line to rectify the problem of the weak traction system. In [6], effective control and energy management methods for subway trains equipped with onboard supercapacitor banks have been proposed to smoothen the dc bus voltage profile. In [7], a control strategy for a tramway network equipped with a supercapacitor-based substation has been proposed. In this article, the energy flow between the moving tramcars and substations is optimized to improve the voltage fluctuations and energy efficiency. An innovative subway traction system based on supercapacitor ESSs without supply rail between two stations has been proposed in [8] and [9]. The ESSs are 
charged using supply rails, which are solely placed at the location of the substations. In [10], an effective method has been proposed for choosing the fundamental characteristic parameters of the supercapacitor-based energy storage substations in dc traction networks. In [11], optimal sizing and energy management of the stationary supercapacitor banks for subway systems have been fulfilled using the genetic algorithm. Using supercapacitor-based solutions, the aforementioned methods mitigate the problem of dc-link voltage variations to a great extent. However, in none of the reviewed works, the problem of instantaneous CPLs has been addressed. In fact, in the $\mathrm{dc}$ traction systems, the upstream converter (source converter consisting of a front-end diode rectifier with a bulk $L C$ filter) and the downstream converter (load converter consisting of a closed-loop traction converter of the train) form a cascaded system. Thus, since the closed-loop load converters have CPL nature, it has been shown that despite the individual stability of each converter, the overall cascaded system can be destabilized when the output impedance of the source converter intersects with the input impedance of the load converter [12, Ch. 1]. This circumstance can take place, for example, when the traction converter of the train operates under overload conditions [13], [14]. The problem of the CPLs in the dc traction systems can be resolved from two perspectives. In the first perspective, a passive bulk capacitor can be added between the $L C$ filter of the source converter and the CPL. Although the passive approach is very simple, it reduces the response speed of the system under normal operating conditions and decreases the energy efficiency. The second perspective is to actively control either the output impedance of the source converter or the input impedance of the traction converter. Accordingly, Zhang et al. [15] proposed an active approach using a new three-phase power configuration. In Zhanh's method, the conventional diode rectifier in the dc substation was replaced by an active three-phase power buffer to enable the regulation of the input impedance of the CPL for maintaining the stability. A battery ESS with a bidirectional dc-dc converter was also utilized to regulate the dc-link voltage. Since most of the already in-service dc traction systems include passive rectifier substations, implementation of this method for the already constructed infrastructure is difficult. In addition, the battery ESSs have relatively low power density and can be damaged under frequent deep charge/discharge conditions. On the other hand, the supercapacitors have better potential to cover peak power demands [16]-[21], [27].

In this article, a new method based on the utilization of onboard supercapacitor-based active stabilizers (SBASs) is proposed for dynamic stabilization of the dc bus in the $\mathrm{dc}$ traction systems. To achieve this goal, a new two-mode control strategy (TMCS) based on model predictive control (MPC) is proposed. Explicitly, this article provides the following contributions.

1) Firstly, this article addresses the problems of dc-link voltage fluctuations and dc-link voltage instability in the dc traction systems at the same time.

2) Secondly, a new TMCS based on the MPC is proposed.

3) Thirdly, the real-time feasibility of the proposed method is demonstrated by a series of hardware-in-the-loop (HIL) experiments on a scaleddown laboratory prototype.

The rest of this article is structured as follows: In Section II, the problems of dc-link voltage variations and dc-link instability in de traction networks are discussed. In Section III, the operating principles of the proposed approach are presented. The simulation and experimental results are provided in Section IV. Finally, Section V provides the main conclusions of this article. In addition, some mathematical proofs are provided in Appendixes A and B at the end of this article.

\section{Problem Description}

Fig. 1(a) shows the schematic of a typical dc traction system. A rectifier substation supplies the dc feeders through a ring ac grid. In addition, a three-phase, full-bridge, dc-ac inverter is used to drive the ac traction motors. The equivalent circuit model of the traction system is also depicted in Fig. 1(b), where $v_{a}, v_{b}$, and $v_{c}$ are the three-phase input voltages of the rectifier substation, $R_{S}$ is the resistance of the ac feeders, $L_{s}$ is the inductance of the ac feeders, $D_{1} D_{6}$ are power diodes of the three-phase full-bridge diode rectifier, $L_{\text {Filter }}$ is the inductance of the $L C$ filter of the rectifier substation, $C_{\text {Filter }}$ is the capacitance of the $L C$ filter, $R_{\text {feeder }}$ and $L_{\text {feeder }}$ are, respectively, the maximum resistance and inductance of the dc feeder, $C_{d}$ is the input capacitance of the traction converter, $V_{\text {bus }}$ is the dc-link voltage, and $S_{1}-S_{6}$ are the insulated gate bipolar transistors (IGBTs) in the traction converter. Moreover, $i_{a}, i_{b}$, and $i_{c}$ are the three-phase motor currents and $\omega_{\text {rotor }}$ and $\theta_{\text {rotor }}$ are the angular speed and position of the rotor, respectively. With regard to the structure of Fig. 1(b), two problems need to be addressed.

\section{A. Increasing Voltage Drop Across the DC Feeder and Voltage Sag in Upstream AC Grid}

According to Fig. 1(a), as the train travels toward the end station, the series resistance of the feeder $\left(R_{\text {Feeder }}\right)$ between the starting station and the train will be increased. Therefore, the traction inverter experiences an increasing voltage drop across its dc-link. In addition, in some de traction systems, the traction network might not have a dc substation at the end station [2]. In such cases, the acceleration of the train from standstill conditions at the end station significantly increases the voltage drop across the line. Furthermore, the voltage sag incidents in the upstream ac grid can also result in a substantial voltage drop on the bus side in a weakened traction system. The foregoing issues can lead to the degradation of the train performance and instability of the dc-link.

\section{B. Destabilizing Effects of the CPLs}

In the closed-loop form, the traction unit and the electric motor exhibit the behavior of a CPL. The incremental resistance of the CPL can be calculated as follows:

$$
R_{\mathrm{CPL}}=\frac{V_{\text {bus }}}{I_{\mathrm{CPL}}}=\frac{P_{\mathrm{CPL}}}{I_{\mathrm{CPL}}^{2}} \stackrel{P_{\mathrm{CPL}}=\text { constant }}{\Rightarrow} \frac{\partial R_{\mathrm{CPL}}}{\partial I_{\mathrm{CPL}}}=-\frac{2 P_{\mathrm{CPL}}}{I_{\mathrm{CPL}}^{3}}
$$

where $R_{\mathrm{CPL}}, I_{\mathrm{CPL}}$, and $P_{\mathrm{CPL}}$ are the resistance, current, and power of the CPL, respectively. According to (1), the CPL 


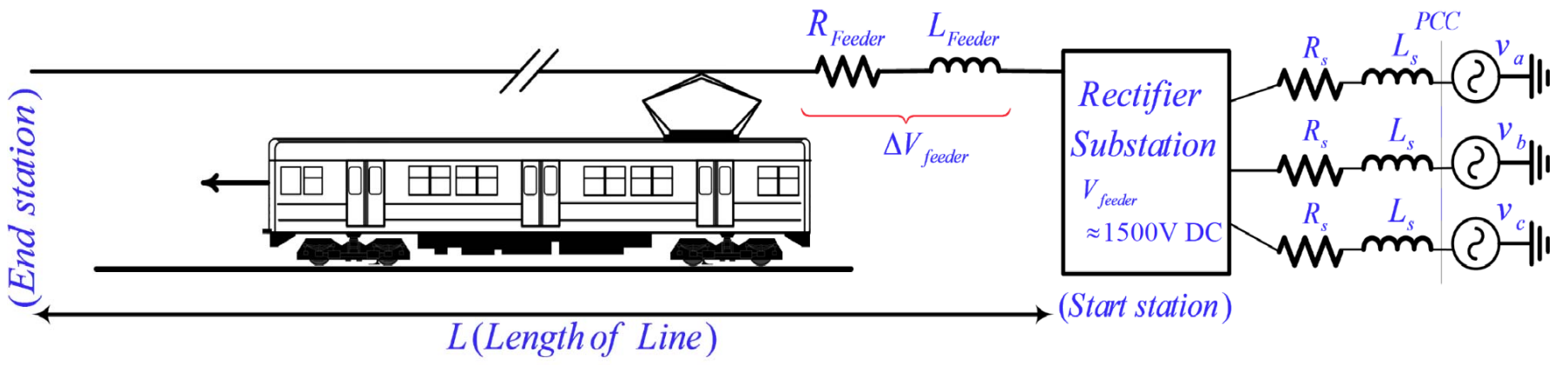

(a)

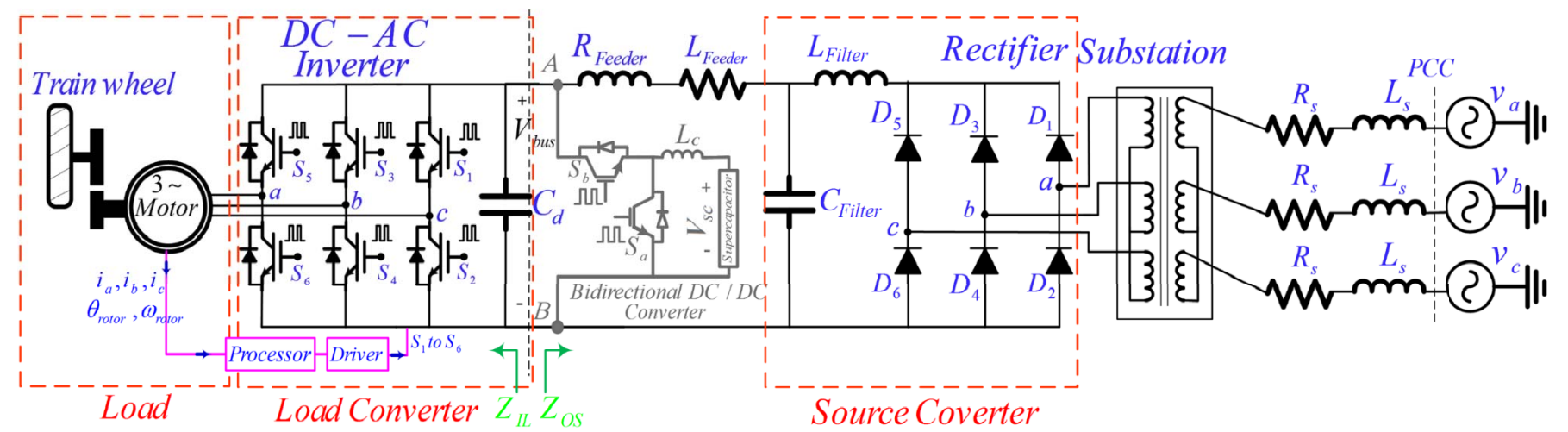

(b)

Fig. 1. (a) Structure of a typical dc traction network. (b) Equivalent circuit model of the traction network.

has a negative incremental resistance, which reflects that any voltage drop resulting from the feeder resistance, voltage sags in the ac grid, etc. increase the CPL current, which in turn increases the voltage drop and aggravates the divergence from the nominal operating point of the dc-link voltage. This phenomenon can lead to system instability when the output impedance of the source converter $Z_{\mathrm{OS}}$ intersects with the input impedance of the traction converter $Z_{\mathrm{IL}}$ [refer to Fig. 1(b)] [12]. Since the source converter in the traction system is a passive converter, $Z_{\mathrm{OS}}$ usually remains constant. However, the dc-link still can be destabilized when $Z_{\mathrm{IL}}$ reduces under heavy-load conditions.

\section{Operating Principles of the Proposed Method}

The operating principles of the proposed SBAS are explained in Sections III-A-III-F.

\section{A. Criterion for DC-Link Stability}

The presence of cascaded converters in Fig. 1(b) can lead to dc-link instability when the output impedance of the source converter $Z_{\mathrm{OS}}$ intersects with the input impedance of CPL $Z_{\mathrm{IL}}$ (detailed discussions on the stability of cascaded converters can be found in [12] and [15]). As discussed before, a wellknown approach for increasing the stability margin is to add a large passive capacitor to the dc-link, across the terminals A and B in Fig. 1(b). The equivalent circuit model of the system in the presence of the passive capacitor is shown in Fig. 2(a). In Fig. 2(a), $R_{\text {ESR }}$ is the ESR of $C_{\text {Filter }}$ and $V_{\text {bus }}$ is the voltage of the dc bus on the inverter side. Considering that the impedance
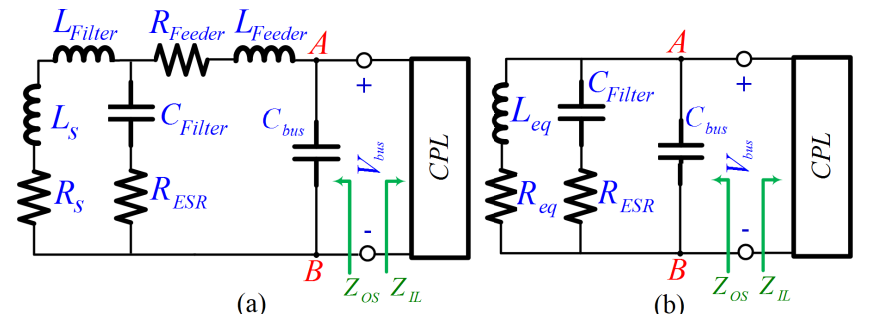

Fig. 2. (a) Equivalent circuit model of Fig. 1(b) considering the passive capacitor $C_{\text {bus }}$ added across the terminals $\mathrm{A}$ and B. (b) Approximated equivalent circuit model of Fig. 2(a).

of the filter capacitor $Z_{C_{\text {Filter }}}$ is very larger than the impedance of the source and the feeder, the equivalent circuit model of Fig. 2(a) can be simplified as shown in Fig. 2(b), in which $L_{\text {eq }}$ is the equivalent inductance of the source converter, filter, and the dc feeder $\left(L_{\mathrm{eq}}=L_{s}+L_{\text {Filter }}+L_{\text {Feeder }}\right)$ and $R_{\text {eq }}$ is the equivalent resistance including the source resistance and the feeder resistance $\left(R_{\text {eq }}=R_{s}+R_{\text {Feeder }}\right)$. With some simplifications and considering that the maximum of $Z_{\mathrm{OS}}(s)$, i.e., $\left|Z_{\mathrm{OS} \text {, max }}\right|$, occurs at $S=1 /\left(L_{\text {eq }} C_{\text {Filter }}\right)^{1 / 2}$ (with $S$ being the Laplace index), one can write

$$
\left|Z_{\mathrm{OS}, \max }\right|=\frac{L_{\mathrm{eq}}}{\left(C_{\text {Filter }}+C_{\mathrm{bus}}\right)\left(R_{\mathrm{eq}}+R_{\mathrm{ESR}}\right)} .
$$

To guarantee the stability of the dc-link, $Z_{\mathrm{IL}}$ and $Z_{\mathrm{OS}}$ should have no intersection [12], which can be realized when the following condition is satisfied:

$$
\left|Z_{\mathrm{OS}, \max }\right| \leq Z_{I L}=\frac{V_{\text {bus }}^{2}}{P_{\mathrm{CPL}}} .
$$


From (2) and (3), the minimum required capacitance of $C_{\text {bus }}$ for maintaining the stability of the dc-link can be obtained using the following condition:

$$
C_{\text {bus }} \geq \frac{L_{\text {eq }} P_{\mathrm{CPL}}}{V_{\text {bus }}^{2}\left(R_{\mathrm{ESR}}+R_{\mathrm{eq}}\right)}-C_{\text {Filter }} .
$$

From (4), it can be seen that based on the values of $V_{\text {bus }}$ and $P_{\mathrm{CPL}}$, the required $C_{\text {bus }}$ varies. In fact, as the level of voltage drop increases, a larger dc-link capacitance is needed for satisfying (4). Hence, in the passive solution, the value of $C_{\text {bus }}$ should be selected considering the worst conditions (maximum load and worst case voltage sag conditions), that is, a passive capacitor with a relatively large capacitance should be inserted at the dc-link to guarantee the stability under all the operating conditions. However, a large capacitor is bulky and it also lowers the efficiency and response speed of the system, which is undesirable. In this article, the value of $C_{\text {bus }}$ is adaptively controlled using the proposed SBAS with TMCS.

\section{B. Proposed SBAS With TMCS}

The schematic of the proposed SBAS is depicted with the gray color in Fig. 2(b). A supercapacitor bank is connected across the terminals $\mathrm{A}$ and $\mathrm{B}$ through a dc-dc bidirectional buck-boost converter. The SBAS is installed onboard at the dc-link of each traction inverter. Since it is assumed that the supercapacitor has a lower voltage profile than the dc-link, the SBAS is controlled in the boost mode whenever the dc-link voltage is below the rated voltage. The proposed TMCS consists of two separate control algorithms, namely primary and secondary control modes, to address the stability and voltage regulation tasks, respectively. In the primary control mode, an effective control method is used to adaptively control the value of $C_{\text {bus }}$ for maintaining the system stability. The primary control is fulfilled by controlling the SBAS current $i_{\text {SBAS }}$ using an MPC-based control approach. When the stability of the system is assured by the primary control mode, small deviations from the reference dc-link voltage is compensated by controlling the output voltage of the SBAS in the socalled secondary control mode. The switching between the two control modes is decided based on the derived stability criterion in (4). The structures of the proposed SBAS and the TMCS are shown in Fig. 3. The threshold for determining the control mode is conservatively selected based on (4), as follows:

$$
\text { threshold }=\left(C_{\text {bus }}-\gamma\left(\frac{L_{\mathrm{eq}} P_{\mathrm{CPL}}}{V_{\mathrm{bus}}^{2}\left(R_{s}+R_{\mathrm{eq}}\right)}-C\right)\right) .
$$

In (5), $\gamma$ is considered to be 1.2 for keeping a reasonable stability margin. The threshold value of (5) is computed in real-time to determine the control mode. When the threshold $\geq 0$, the system operates under stable conditions, and thus the secondary control mode is activated to tightly regulate the dc-link voltage. When the threshold $<0$, the primary control mode is activated to maintain the stability of the system by increasing the value of $C_{\text {bus. }}$. As soon as the stability criterion is satisfied, the secondary control mode is activated once again to minimize the difference between the

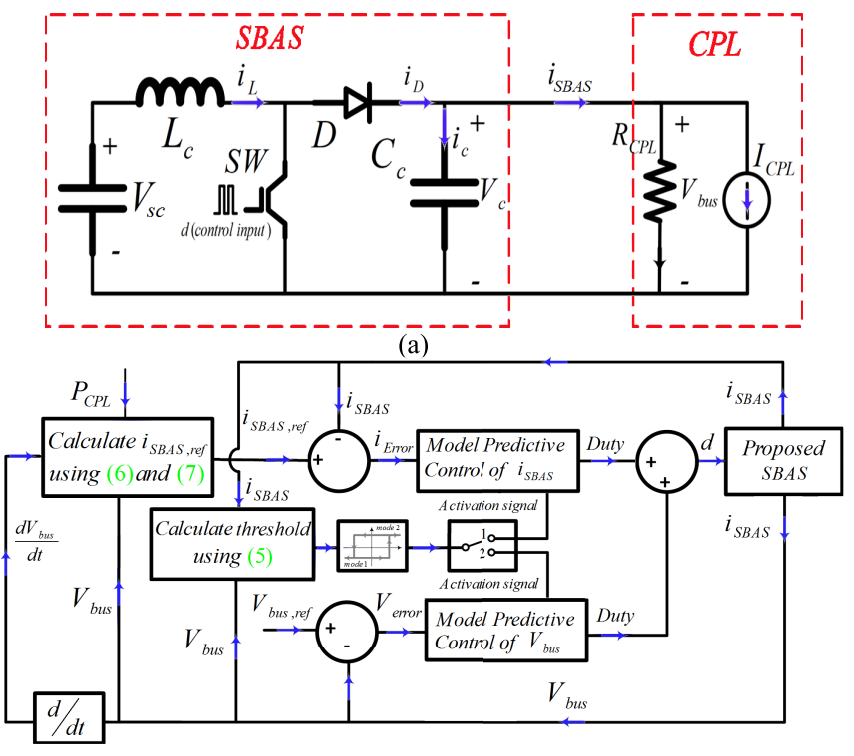

(b)

Fig. 3. (a) Structure of the proposed SBAS. (b) Proposed TMCS

dc-link voltage and its reference value. A hysteresis function is used to avoid unwanted chattering between the two control modes when the threshold value is relatively small. When a control mode is deactivated, its respective controller is turnedoff to increase the computational efficiency. In the primary control mode, the SBAS is treated as an adaptive capacitor, and thus one can write

$$
i_{\mathrm{SBAS}}=-C_{\mathrm{bus}} \times \frac{d V_{\mathrm{bus}}}{d t} .
$$

Based on (5), the required value of $C_{\text {bus }}$ is conservatively decided by the following equation:

$$
C_{\text {bus }}=1.2\left(\frac{L_{\mathrm{eq}} P_{\mathrm{CPL}}}{V_{\text {bus,worst }}^{2}\left(R_{s}+R_{\mathrm{eq}}\right)}-C\right)
$$

where $V_{\text {bus,worst }}$ denotes the worst dc bus voltage condition. Thus, the reference current of SBAS for the primary control mode is constructed based on (6) and (7) and the instantaneous values of the dc-link voltage and the CPL power. In addition, the reference voltage in the second control mode is set to the rated dc-bus voltage. In both the control modes, MPC-based control schemes are adopted to effectively avoid any unwanted transient response such as overshoots, which can increase the risk of system instability. The model derivation and MPC formulation are discussed in Section III-C.

\section{SBAS State-Space Model and MPC Formulation}

As seen in Fig. 3(a), at a given operating point $\left(I_{\mathrm{CPL}}=P_{\mathrm{CPL}} / V_{\mathrm{bus}}\right)$, the CPL is approximated by a negative resistance paralleled by a constant current source (see Appendix A). In order to implement the proposed TMCS, the state-space model of the SBAS should be derived. In the following, the system modeling and formulations of the control algorithm for the primary control mode are presented. Later, it will be shown that the same model and formulations can be used with simple variations for designing the second control 
mode. Using the averaging concept, the large-signal statespace model of the SBAS shown in Fig. 3(a) is obtained as follows:

$$
\begin{aligned}
& {\left[\begin{array}{l}
\frac{d i_{L}}{d t} \\
\frac{d V_{c}}{d t}
\end{array}\right]} \\
& =\left[\begin{array}{cc}
0 & \frac{-(1-D)}{L_{C}} \\
\frac{(1-D)}{C_{c}} & \frac{-1}{R_{\mathrm{CPL}} C_{c}}
\end{array}\right]\left[\begin{array}{c}
i_{L} \\
V_{c}
\end{array}\right]+\left[\begin{array}{cc}
\frac{1}{L_{c}} & 0 \\
0 & \frac{-1}{C_{c}}
\end{array}\right]\left[\begin{array}{c}
V_{\mathrm{in}} \\
I_{\mathrm{CPL}}
\end{array}\right] \\
& y=i_{\mathrm{SBAS}}=\left[\begin{array}{ll}
0 & \frac{1}{R_{\mathrm{CPL}}}
\end{array}\right]\left[\begin{array}{l}
i_{L} \\
V_{c}
\end{array}\right]+\left[\begin{array}{ll}
0 & 1
\end{array}\right]\left[\begin{array}{c}
V_{\mathrm{in}} \\
I_{\mathrm{CPL}}
\end{array}\right]
\end{aligned}
$$

where $i_{L}$ and $V_{c}$ are the inductor current and the output capacitor voltage of the SBAS, which are considered as the state variables of the system. In addition, the SBAS current is considered as the model output, $D$ is the duty cycle of the switch $\mathrm{SW}$, and $V_{\text {in }}$ (the same $V_{\mathrm{sc}}$ ) is the measurable supercapacitor voltage. The state-space equations of (8) are linearized around an equilibrium point using the small-signal approach. The small-signal model of the SBAS is obtained as follows:

$$
\begin{aligned}
{\left[\begin{array}{c}
\frac{d \hat{i}_{L}}{d t} \\
\frac{d \hat{V}_{c}}{d t}
\end{array}\right]=} & {\left[\begin{array}{cc}
0 & \frac{-(1-D)}{L_{c}} \\
\frac{(1-D)}{C_{c}} & \frac{-1}{R_{\mathrm{CPL}} C_{c}}
\end{array}\right]\left[\begin{array}{c}
\hat{i}_{L} \\
\hat{V}_{c}
\end{array}\right] } \\
& +\left[\begin{array}{c}
\frac{-V_{c, \mathrm{ss}}}{C_{c}} \\
\frac{I_{L, \mathrm{ss}}}{L_{c}}
\end{array}\right] d+\left[\begin{array}{cc}
\frac{1}{L_{c}} & 0 \\
0 & \frac{-1}{C_{c}}
\end{array}\right]\left[\begin{array}{c}
\hat{v}_{\mathrm{in}} \\
\hat{i}_{\mathrm{CPL}}
\end{array}\right] \\
y= & \hat{i}_{\mathrm{SBAS}}=\left[\begin{array}{ll}
0 & \frac{1}{R_{\mathrm{CPL}}}
\end{array}\right]\left[\begin{array}{c}
\hat{i}_{L} \\
\hat{V}_{c}
\end{array}\right]+\left[\begin{array}{ll}
0 & 1
\end{array}\right]\left[\begin{array}{c}
\hat{v}_{\mathrm{in}} \\
\hat{i}_{\mathrm{CPL}}
\end{array}\right]
\end{aligned}
$$

where $\hat{V}_{c}, \hat{i}_{L}, \hat{v}_{\text {in }}$, and $\hat{i}_{\mathrm{CPL}}$ are, respectively, the values of $V_{c}, i_{L}, V_{\mathrm{in}}$, and $I_{\mathrm{CPL}}$ in the small-signal analysis. In addition, $V_{c, \mathrm{ss}}, I_{L, \mathrm{ss}}$, and $D$ are the steady-state values of $V_{c}, I_{L}$, and duty cycle of the switch SW. Using the Laplace transform, the control for $V_{c}$ transfer function of the SBAS small-signal state-space model can be obtained as follows:

$$
\begin{aligned}
S^{2} V_{c}(s) & \\
= & -\frac{(1-D)^{2}}{L_{c} C_{c}} V_{c}(s)+\frac{(1-D)}{L_{c} C_{c}} V_{\mathrm{in}}(s)-\frac{(1-D) V_{c, \mathrm{ss}}}{C_{c}^{2}} d(s) \\
& -\frac{1}{R_{\mathrm{CPL}} C_{c}} S V_{c}(s)-\frac{1}{C_{c}} S I_{\mathrm{CPL}}(s)+\frac{I_{L, \mathrm{ss}}}{L_{c}} S d(s)
\end{aligned}
$$

where $S$ denotes the Laplace index. Substituting $V_{c}(s)=R_{\mathrm{CPL}}\left(I_{\mathrm{SBAS}}(s)-I_{\mathrm{CPL}}(s)\right)$ yields

$$
\begin{aligned}
& I_{\mathrm{SBAS}}(s)\left[S^{2} R_{\mathrm{CPL}}+S \frac{1}{C_{c}}+\frac{(1-D)^{2} R_{\mathrm{CPL}}}{L_{c} C_{c}}\right] \\
& =d(s)\left[\frac{I_{L, \mathrm{ss}}}{L_{c}} S-\frac{(1-D) V_{c, \mathrm{ss}}}{C_{c}^{2}}\right]+V_{\mathrm{in}}(s) \frac{(1-D)}{L_{c} C_{c}} \\
& \quad+I_{\mathrm{CPL}}(s)\left[S^{2} R_{\mathrm{CPL}}+\frac{(1-D)^{2} R_{\mathrm{CPL}}}{L_{c} C_{c}}\right] .
\end{aligned}
$$

For the implementation purpose, (11) should be written in the discrete form as follows:

$$
\begin{aligned}
& \underbrace{\left[\frac{R_{\mathrm{CPL}}}{T_{s}}+\frac{1}{T_{s} C_{c}}+\frac{(1-D)^{2} R_{\mathrm{CPL}}}{L_{c} C_{c}}\right]}_{=} I_{\mathrm{SBAS}}(k) \\
& =\underbrace{\left[\frac{2 R_{\mathrm{CPL}}}{T_{s}}+\frac{1}{T_{s} C_{c}}\right]}_{K_{1}} I_{\mathrm{SBAS}}(k-1)+\underbrace{\frac{-R_{\mathrm{CPL}}}{T_{s}}}_{K_{3}} I_{\mathrm{SBAS}}(k-2) \\
& +\underbrace{\left[\frac{I_{L, \mathrm{ss}}}{T_{s} L_{c}}-\frac{(1-D) V_{c, \mathrm{ss}}}{C_{c}^{2}}\right]}_{K_{4}} d(k)+\underbrace{\frac{-I_{L, \mathrm{ss}}}{T_{s} L_{c}}}_{K_{5}} d(k-1) \\
& +\underbrace{\frac{(1-D)}{L_{c} C_{c}}}_{K_{6}} V_{\mathrm{in}}(k)+\underbrace{\left[\frac{R_{\mathrm{CPL}}}{T_{s}}+\frac{(1-D)^{2} R_{\mathrm{CPL}}}{L_{c} C_{c}}\right]}_{K_{7}} I_{\mathrm{CPL}}(k) \\
& +\underbrace{\frac{-2 R_{\mathrm{CPL}}}{T_{s}}}_{K_{8}} I_{\mathrm{CPL}}(k-1)+\underbrace{\frac{R_{\mathrm{CPL}}}{T_{s}}}_{K_{9}} I_{\mathrm{CPL}}(k-2)
\end{aligned}
$$

where $T_{s}$ is the sampling time, $k$ is the time index, $I_{\mathrm{SBAS}}$ is the controlled output, and $d$ is the control input. In addition, $V_{\text {in }}$ and $I_{\mathrm{CPL}}$ are considered as the measurable system disturbances. The proposed MPC-based control algorithm for the primary control mode consists of applying a control sequence, which minimizes a multistage cost function $(\mathrm{CF})$ as follows:

$$
\begin{aligned}
J\left(N_{1}, N_{2}\right)=\sum_{j=1}^{N_{1}} \sigma_{1}\left[\hat{I}_{\mathrm{SBAS}}(k\right. & +j \mid k)-\omega(k+j)]^{2} \\
& +\sum_{j=1}^{N_{2}} \sigma_{2}[\Delta d(k+j-1)]^{2}
\end{aligned}
$$

where $\sigma_{1}, \sigma_{2}, N_{1}, N_{2}$, and $\omega$ are the normalized output weighting factor, normalized control weighting factor, prediction horizon, control horizon, and desired reference trajectory, respectively. In addition, $\hat{I}_{\mathrm{SBAS}}(k+j \mid k)$ denotes the prediction of the output $I_{\text {SBAS }}$ at the sample $(k+j)$ on the premise that the history of $I_{\mathrm{SBAS}}$ up to the instant $k$ is available. In the $\mathrm{CF}$ of (13), the prediction of $I_{\mathrm{SBAS}}$ for $1 \leq j \leq N_{1}$ must be obtained. To fulfill this task, the SBAS model of (12) can be rearranged as follows:

$$
\begin{aligned}
& \underbrace{\left(K_{1}-K_{2} z^{-1}-K_{3} z^{-2}\right)}_{A\left(z^{-1}\right)} I_{\mathrm{SBAS}}(k) \\
& =\underbrace{\left(K_{4}+K_{5} z^{-1}\right)}_{B\left(z^{-1}\right)} d(k)+\underbrace{K_{6}}_{D_{1}\left(z^{-1}\right)} V_{\mathrm{in}}(k) \\
& +\underbrace{\left(K_{7}+K_{8} z^{-1}+K_{9} z^{-2}\right)}_{D_{2}\left(z^{-1}\right)} I_{\mathrm{CPL}}(k)
\end{aligned}
$$

where $z^{-1}$ is the unit back-shift operator and $A, B, D_{1}$, and $D_{2}$ are $z$-polynomials. In addition, $V_{\text {in }}(k)$ and $I_{\mathrm{CPL}}(k)$ denote the measurable disturbances of the system in sample $k$. Typically, a general formulation for the output predictor can be obtained using the well-known Diophantine equation [22]. 
Here, the following Diophantine equation is considered:

$$
\begin{gathered}
1=E_{j}\left(z^{-1}\right) \tilde{A}\left(z^{-1}\right)+z^{-j} F_{j}\left(z^{-1}\right) \\
\text { where } \tilde{A}\left(z^{-1}\right)=\Delta A\left(z^{-1}\right) .
\end{gathered}
$$

The polynomials $E_{j}$ and $F_{j}$ have degrees of $j-1$ and two (the same degree of polynomial $A$ ), respectively. These polynomials can be easily obtained by dividing 1 by $\tilde{A}\left(z^{-1}\right)$ until the remainder can be factorized as $z^{-j} F_{j}\left(z^{-1}\right)$ [22]. The polynomial $E_{j}\left(z^{-1}\right)$ is equal to the quotient of the division. Multiplying (14) by $\Delta E_{j}\left(z^{-1}\right) z^{j}$, one can write

$$
\begin{aligned}
E_{j}\left(z^{-1}\right) \tilde{A}\left(z^{-1}\right) I_{\mathrm{SBAS}}(k+j) \\
=E_{j}\left(z^{-1}\right) B\left(z^{-1}\right) \Delta d(k+j-1) \\
\quad+E_{j}\left(z^{-1}\right) D_{1}\left(z^{-1}\right) \Delta V_{\mathrm{in}}(k+j) \\
\quad+E_{j}\left(z^{-1}\right) D_{2}\left(z^{-1}\right) \Delta I_{\mathrm{CPL}}(k+j) .
\end{aligned}
$$

Using (16) and with some manipulations, the expected value of $I_{\mathrm{SBAS}}(k+j)$ can be obtained as follows:

$$
\begin{aligned}
\hat{I}_{\mathrm{SBAS}}(k+j \mid k)= & E\left[I_{\mathrm{SBAS}}(k+j)\right]=F_{j}\left(z^{-1}\right) I_{\mathrm{SBAS}}(k) \\
& +E_{j}\left(z^{-1}\right) B\left(z^{-1}\right) \Delta d(k+j-1) \\
& +E_{j}\left(z^{-1}\right) D_{1}\left(z^{-1}\right) \Delta V_{\mathrm{in}}(k+j) \\
& +E_{j}\left(z^{-1}\right) D_{2}\left(z^{-1}\right) \Delta I_{\mathrm{CPL}}(k+j) .
\end{aligned}
$$

By changing the polynomials $E_{j}\left(z^{-1}\right) D_{1}\left(z^{-1}\right)=$ $H_{1 j}\left(z^{-1}\right)+z^{-j} H_{1 j}^{\prime}\left(z^{-1}\right), E_{j}\left(z^{-1}\right) D_{2}\left(z^{-1}\right)=H_{2 j}\left(z^{-1}\right)+$ $z^{-j} H_{2 j}^{\prime}\left(z^{-1}\right)$, and $E_{j}\left(z^{-1}\right) B\left(z^{-1}\right)=G_{j}\left(z^{-1}\right)+z^{-j} G_{j}^{\prime}\left(z^{-1}\right)$, the prediction equation of (17) $\left(\hat{I}_{\mathrm{SBAS}}(k+j \mid k)\right)$ can be rewritten as follows:

$$
\begin{aligned}
\hat{I}_{\mathrm{SBAS}} & (k+j \mid k) \\
= & G_{j}\left(z^{-1}\right) \Delta d(k+j-1)+H_{1 j}\left(z^{-1}\right) \Delta V_{\mathrm{in}}(k+j) \\
& +H_{2 j}\left(z^{-1}\right) \Delta I_{\mathrm{CPL}}(k+j)+G_{j}^{\prime}\left(z^{-1}\right) \Delta d(k-1) \\
& +H_{1 j}^{\prime}\left(z^{-1}\right) \Delta V_{\mathrm{in}}(k)+H_{2 j}^{\prime}\left(z^{-1}\right) \Delta I_{\mathrm{CPL}}(k) \\
& +F_{j}\left(z^{-1}\right) I_{\mathrm{SBAS}}(k)
\end{aligned}
$$

where degrees of $H_{1 j}\left(z^{-1}\right), H_{2 j}\left(z^{-1}\right)$, and $G_{j}\left(z^{-1}\right)$ are $j-1$. In (18), the last four terms on the right side of the equation depend on the past values of the SBAS output, the CPL current, the supercapacitor voltage, and the input duty cycle, which are all known quantities. Since the values of $V_{\text {in }}$ and $I_{\mathrm{CPL}}$ experience a negligible change during each epoch of the control algorithm, one can deduce that $\Delta V_{\text {in }}(k+j)=$ $\Delta I_{\mathrm{CPL}}(k+j)=0$. Therefore, only the term $\Delta d(k+j-1)$ depends on the future values of the control signal, which is obtained by substituting (18) in $\mathrm{CF}$ of (13) and solving the CF. Considering a prediction horizon equal to two $\left(N_{1}=2\right)$, the needed predictor equations are calculated as follows:

$$
\begin{aligned}
& \hat{I}_{\text {SBAS }}(k+1 \mid k) \\
& =\underbrace{\frac{K_{4}}{K_{1}}}_{G_{1}\left(z^{-1}\right)} \Delta d(k)+\underbrace{\frac{K_{4}}{K_{1}}}_{H_{11}\left(z^{-1}\right)} \Delta V_{\text {in }}(k+1) \\
& +\underbrace{\frac{K_{7}}{K_{1}}}_{H_{21}\left(z^{-1}\right)} \Delta I_{\mathrm{CPL}}(k+1)+\underbrace{\frac{K_{5}}{K_{1}}}_{G_{1}^{\prime}\left(z^{-1}\right)} \Delta d(k-1) \\
& +\underbrace{\left(\frac{K_{8}}{K_{1}}+\frac{K_{9}}{K_{1}} z^{-1}\right)}_{H_{21}^{\prime}\left(z^{-1}\right)} \Delta I_{\mathrm{CPL}}(k) \\
& +\underbrace{\left(\frac{K_{1}+K_{2}}{K_{1}}-\frac{K_{2}-K_{3}}{K_{1}} z^{-1}-\frac{K_{3}}{K_{1}} z^{-2}\right)}_{F_{1}\left(z^{-1}\right)} I_{\mathrm{SBAS}}(k) .
\end{aligned}
$$

The procedure for deriving the predictor equations are explained with details in Appendix B. The $\mathrm{CF}$ and predictor equations of (13), (19), and (20), as shown at the bottom of the next page, are related to the primary control mode. The $\mathrm{CF}$ of the secondary control mode can be written as follows:

$$
\begin{aligned}
J^{\prime}\left(N_{1}^{\prime}, N_{2}^{\prime}\right)=\sum_{j=1}^{N_{1}^{\prime}} \sigma_{1}^{\prime}\left[\hat{V}_{c}(k+j \mid k)-\varpi(k+j)\right]^{2} & \\
& +\sum_{j=1}^{N_{2}^{\prime}} \sigma_{2}^{\prime}[\Delta d(k+j-1)]^{2}
\end{aligned}
$$

where $\sigma_{1}^{\prime}, \sigma_{2}^{\prime}, N_{1}^{\prime}, N_{2}^{\prime}$, and $\varpi$ are the normalized output weighting factor, normalized control weighting factor, prediction horizon, control horizon, and the desired dc-bus voltage trajectory, respectively. The prediction model of $\hat{V}_{c}(k+j \mid k)$ can be easily deduced using the prediction model of $\hat{I}_{\mathrm{SBAS}}(k)$ obtained in (17). In fact, according to the second formula in (9), $\hat{V}_{c}$ can be written as a function of $\hat{I}_{\mathrm{SBAS}}$ as follows:

$$
\hat{V}_{c}=R_{\mathrm{CPL}}\left(\hat{i}_{\mathrm{SBAS}}-\hat{i}_{\mathrm{CPL}}\right) \text {. }
$$

Thus, the prediction equation for $\hat{V}_{c}$ can be obtained as follows:

$$
\begin{aligned}
\hat{V}_{c}(k+ & j \mid k) \\
= & F_{j}\left(z^{-1}\right) V_{c}(k)+R_{\mathrm{CPL}} E_{j}\left(z^{-1}\right) B\left(z^{-1}\right) \Delta d(k+j-1) \\
& +R_{\mathrm{CPL}} E_{j}\left(z^{-1}\right) D_{1}\left(z^{-1}\right) \Delta V_{\text {in }}(k+j) \\
& +R_{\mathrm{CPL}} E_{j}\left(z^{-1}\right)\left(D_{2}\left(z^{-1}\right)-A\left(z^{-1}\right)\right) \Delta I_{\mathrm{CPL}}(k+j) .
\end{aligned}
$$

The one-step ahead and two-step ahead prediction models of $\hat{V}_{c}$ can then be easily derived using (23), (B.2), and (B.3). The detailed calculations are not included here due to the space limit.

\section{Discussion About the Selection of CF Parameters and Constraints}

As a general rule, longer prediction and control horizons may provide a better control performance. However, increasing 
the prediction and control horizons reduces the computational efficiency. Therefore, a tradeoff between the needed control performance and computational cost should be made. Moreover, the control horizon must be necessarily shorter than the prediction horizon. Based on these considerations, the prediction and control horizons of the CFs $J$ and $J^{\prime}$ are selected as follows:

$$
N_{1}=N_{1}^{\prime}=2, \quad N_{2}=N_{2}^{\prime}=1 .
$$

The normalized weighting factors $\sigma_{1}, \sigma_{2}, \sigma_{1}^{\prime}$, and $\sigma_{2}^{\prime}$ determine the relative importance of their corresponding terms in the CFs. The parameters $\sigma_{1}$ and $\sigma_{1}^{\prime}$ are normalized by the steadystate value of $I_{\mathrm{SBAS}}$. In addition, $\sigma_{1}^{\prime}$ and $\sigma_{2}^{\prime}$ are normalized to the rated value of the control action (duty cycle $=1$ ). Using the method in [23], the weighting factors are chosen as follows:

$$
\sigma_{1}=0.6, \quad \sigma_{1}^{\prime}=\sigma_{2}=\sigma_{2}^{\prime}=0.5 .
$$

In the proposed TMCS, some constraints are also considered for protection purposes. For example, in order to avoid the gain polarity inversion and the excessive inductor current, the maximum value of the control action (duty cycle) $d_{\max }$ is limited during the optimization of the CFs. In addition, two constraints on the output variables $I_{\mathrm{SBAS}}$ and $V_{c}$ are considered. Based on a worst case scenario in which the dc-link voltage can be as low as 0.67 p.u. (according to the standard EN 50163, for the considered $1500-\mathrm{V}$ dc traction substation, the lowest steady-state dc-link voltage can be $1000-\mathrm{V} \mathrm{dc}$ ), the maximum and minimum values of $I_{\text {SBAS }}$ and $V_{c}$ are set to 1.1 and 0.67 p.u., respectively. Finally, the supercapacitor Depth-of-Discharge (DoD) is set to 0.7 p.u.

\section{E. Kinematic Model of the Vehicle}

In this section, the dynamic tractive requirements of the electric train are modeled. Fig. 4 shows the different forces acting against the electric coach. These forces include four different components as follows [16], [24], [25].

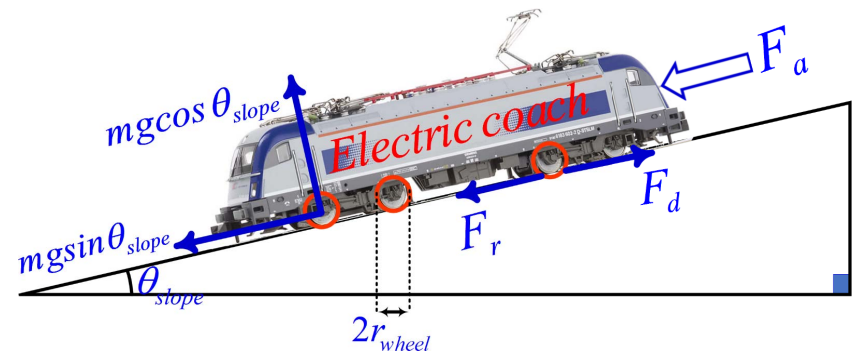

Fig. 4. Forces acting against the electric coach.

1) Rolling Resistance Force: The rolling resistance force is the required force for overcoming the friction between the rail and the wheels of the train. The rolling resistance force can be represented as follows:

$$
F_{r}=K_{\text {rolling }} \operatorname{mg} \cos \theta_{\text {slope }}
$$

where $K_{\text {rolling }}$ is the rolling resistance coefficient, $m$ is the overall weight of the coach $(\mathrm{kg})$ including the passengers' weight, $g$ is the gravitational constant $\left(\mathrm{m} / \mathrm{s}^{2}\right)$, and $\theta_{\text {slope }}$ is the slope angle of the traveling path (degree).

2) Gradient Force of the Travel Path: As seen in Fig. 4, when the coach travels along a steep path, a gradient force will be created by gravity, which acts against the train. The gradient force can be expressed as follows:

$$
F_{g}=\mathrm{mg} \sin \theta_{\text {slope }} \text {. }
$$

3) Aerodynamic Resistance Force: The aerodynamic force is created by the airstream, which acts against the electric coach. The aerodynamic force can be modeled as follows:

$$
F_{a}=\frac{1}{2} \rho C_{d} A_{f} v^{2}
$$

where $\rho$ is the air density $\left(\mathrm{kg} / \mathrm{m}^{3}\right), C_{d}$ is the drag force coefficient, $A_{f}$ is the frontal area of the coach $\left(\mathrm{m}^{2}\right)$, and $v$ is the linear velocity of the electric train $(\mathrm{m} / \mathrm{s})$.

4) Transient Force: The transient force is the force acting during the acceleration or deceleration of the train and can be simply written according to the well-known second

$$
\begin{aligned}
& \hat{I}_{\text {SBAS }}(k+2 \mid k)=\underbrace{\left(\frac{K_{4}}{K_{1}}+\left(\frac{K_{4}}{K_{1}^{2}}\left(K_{1}+K_{2}\right)+\frac{K_{5}}{K_{1}}\right) z^{-1}\right)}_{G_{2}\left(z^{-1}\right)} \Delta d(k+1)+K_{6} \underbrace{\left(\frac{1}{K_{1}}+\frac{K_{1}+K_{2}}{K_{1}^{2}} z^{-1}\right)}_{H_{12}\left(z^{-1}\right)} \Delta V_{\text {in }}(k+2) \\
& +\underbrace{\left(\frac{K_{7}}{K_{1}}+\left(\frac{K_{7}}{K_{1}^{2}}\left(K_{1}+K_{2}\right)+\frac{K_{8}}{K_{1}}\right) z^{-1}\right)}_{H_{22}\left(z^{-1}\right)} \Delta I_{\mathrm{CPL}}(k+2) \\
& +\underbrace{\frac{K_{5}}{K_{1}}\left(K_{1}+K_{2}\right)}_{G_{2}^{\prime}\left(z^{-1}\right)} \Delta d(k-1)+\underbrace{\left(\frac{K_{8}}{K_{1}^{2}}\left(K_{1}+K_{2}\right)+\frac{K_{9}}{K_{1}}+\frac{K_{9}}{K_{1}^{2}}\left(K_{1}+K_{2}\right) z^{-1}\right)}_{H_{22}^{\prime}\left(z^{-1}\right)} \Delta I_{\mathrm{CPL}}(k) \\
& +\underbrace{\left(\frac{\left(K_{1}+K_{2}\right)^{2}}{K_{1}^{2}}-\frac{K_{2}-K_{3}}{K_{1}}-\left(\frac{\left(K_{1}+K_{2}\right)\left(K_{2}-K_{3}\right)}{K_{1}^{2}}+\frac{K_{3}}{K_{1}}\right) z^{-1}-\frac{K_{3}\left(K_{1}+K_{2}\right)}{K_{1}^{2}} z^{-2}\right)}_{F_{2}\left(z^{-1}\right)} I_{\mathrm{SBAS}}(k)
\end{aligned}
$$




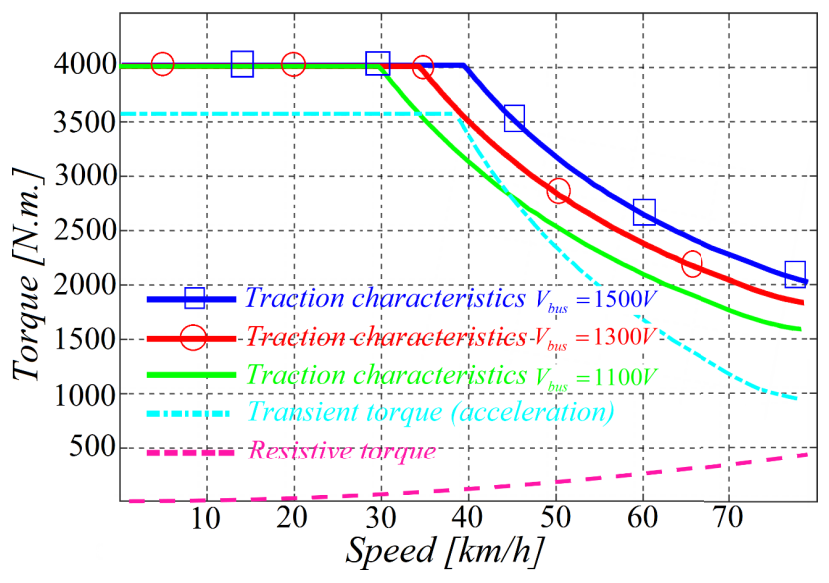

Fig. 5. Traction characteristics of two 250-kW motors (at different dc-link voltage levels) and the overall resistive torque.

law of Newton as $F_{\text {transient }}=m a$ with $a$ being the train acceleration $\left(\mathrm{m} / \mathrm{s}^{2}\right)$.

Therefore, the overall drive force needed for the propulsion of the electric coach can be obtained as follows:

$$
F_{d}=m \frac{d v}{d t}+\underbrace{K_{\text {rolling }} \operatorname{mgcos} \theta_{\text {slope }}+\operatorname{mg} \sin \theta_{\text {slope }}+\frac{1}{2} \rho C_{d} A v_{f}^{2}}_{\text {resistive forces }} .
$$

Therefore, at each instant, the required tractive force of the train can be obtained using (27). The tractive force can be simply transformed into the tractive torque using $T_{d}=F_{d} \times r_{\text {wheel }}$, in which $r_{\text {wheel }}$ is the radius of the wheel of the coach. Finally, the motor torque can be easily calculated taking the gear ratio into account as follows:

$$
\left.T_{\text {motor }}=T_{d} / \text { (gear ratio }\right) \text {. }
$$

Consequently, to simulate the kinematics of the electric train, the model of the traction system in Fig. 1(b) is used and the motor load changed continuously during the simulation according to (27) and (28). In this article, the electric train described in [6] is considered for the simulations. The train is manufactured by CAF S.A. (Construcciones y Auxiliar de Ferrocarriles) and is currently in operation on Rome underground lines [6]. The electric train consists of six railroad coaches, each having a full load translating mass of $m=46300 \mathrm{~kg}$. In addition, each coach is equipped with two $250-\mathrm{kW}$ electrical traction motors, which enables the train to reach a maximum acceleration rate of $a=1.2 \mathrm{~m} / \mathrm{s}^{2}$ and a top speed of $80 \mathrm{~km} / \mathrm{h}$. The electrical substation has a rated dc-link voltage of $1500 \mathrm{~V}$ and the electrical resistance per kilometer of the contact line is $27.6 \mathrm{~m} \Omega / \mathrm{km}$. In Fig. 5, the traction motor characteristics at different dc-link voltage levels and the overall resistive torque for one of the railroad coaches are provided. From Fig. 5, it can be deduced that the two $250-\mathrm{kW}$ traction motors are sufficient to meet the dynamic tractive requirements for one electric coach.

\section{F. Typical Design Example of the SBAS}

Generally, the SBAS should be designed based on the specifications of the traction system, such as the rated dc-link voltage, number of traction motors, weight of the coaches, maximum allowable voltage drop of the dc-link, efficiency, economic considerations, etc. Thus, the exact and optimal design of the SBAS by considering all the aforementioned factors can only be achieved using complex optimization methods, which is beyond the scope of this article. In this section, however, the design guidelines are provided for a typical traction system using simple rules of thumb. Assuming a maximum SBAS boost factor $(\mathrm{BF})$ of 3.5 and a supercapacitor DoD of 0.7 p.u., the rated voltage of the supercapacitor bank can be calculated as follows [26]:

$$
\begin{aligned}
V_{\text {in }, \text { rated }} & =\frac{V_{\text {bus,rated }}}{(1-\text { DoD }) \times \mathrm{BF}_{\text {Limit }}} \\
& =\frac{1500}{(1-0.7) \times 3.5} \approx 1429 \mathrm{~V}
\end{aligned}
$$

where $V_{\text {in,rated }}$ is the rated voltage of the supercapacitor bank, $V_{\text {bus, rated }}$ is the rated voltage of the dc-link, and $\mathrm{BF}_{\text {Limit }}$ is the practical limit of SBAS's BF. Therefore, considering a standard DuraBlue 2.85-V, 2000-A, 3400-F supercapacitor cell from Maxwell Technologies, a supercapacitor bank with a $4 \times 500$ configuration (four parallel rows, 500 series cascaded cells) is selected. Thus, the rated capacitance and the rated current of the whole bank are $C_{\text {sc, rated }}=27.2 \mathrm{~F}$ and $I_{\text {sc, rated }}=8 \mathrm{kA}$, respectively. In addition, considering 0.7-p.u. DoD and a maximum supercapacitor voltage of 0.95 p.u. (for protection purposes), the usable energy of the supercapacitor bank of each traction inverter is calculated as follows:

$$
\begin{aligned}
\Delta E_{\text {usable }}= & \frac{1}{2} C_{\mathrm{sc}, \text { rated }}\left(V_{\text {in, } \max }^{2}-V_{\text {in }, \text { min }}^{2}\right) \\
& \times \stackrel{V_{\text {in, } \max }=0.95 V_{\text {in,rated }}, V_{\text {in, } \min }=0.3 V_{\text {in,rated }}}{\longrightarrow} \\
\Delta E_{\text {usable }}= & 0.5 \times 27.2 \times\left(1357.6^{2}-428.7^{2}\right) \\
\approx & 22 \mathrm{MJ}=6.11 \mathrm{kWh} .
\end{aligned}
$$

The obtained $\Delta E_{\text {usable }}$ is reasonable for typical acceleration events. Other components of the SBAS can be accordingly sized with classical design equations and considering the allowable inductor current and capacitor voltage ripples that a particular application demands.

\section{Results And Discussion}

In order to evaluate the performance of the proposed method, the traction system of Fig. 1(b), the proposed SBAS, and the proposed TMCS are simulated in MATLAB/ SIMULINK. The main ac grid, three-phase power transformer, full-bridge diode rectifier, $L C$ filter, traction converter, electric motor, and the proposed SBAS are exactly simulated according to Fig. 1(b) and using the available blocks from the MATLAB SimPowerSystems library. However, the kinematics of the traction system is simulated with an equation-based approach using (24)-(28). The speed of the traction motor is tightly regulated based on a closed-loop proportional integrator (PI) speed controller. The sampling time of the TMCS is set to $1 \mathrm{~ms}$. In addition, the pulse wide modulation (PWM) frequency of the traction inverter and the SBAS is set to $5 \mathrm{kHz}$. Detailed simulation parameters are listed in Table I. 
TABLE I

Parameters of THE Simulated System

\begin{tabular}{|c|c|c|c|}
\hline Parameter & value & Parameter & value \\
\hline$V_{\text {bus,rated }}$ & $1500 \mathrm{~V}$ & Gear ratio & $1: 6$ \\
\hline$V_{s c, \text { rated }}$ & $1429 \mathrm{~V}$ & Rated motor power & $250 \mathrm{~kW}$ \\
\hline$I_{s c, \text { rated }}$ & $8 k A$ & No. of motors & 2 \\
\hline$C_{s c \text {,rated }}$ & $27.2 F$ & Top speed & $80 \mathrm{~km} / \mathrm{h}$ \\
\hline$R_{\text {Feeder }}$ & $27.6 \mathrm{~m} \Omega / \mathrm{km}$ & Max. acceleration & $1.2 \mathrm{~m} / \mathrm{s}^{2}$ \\
\hline$L$ (length) & $1.6 \mathrm{~km}$ & Max. deceleration & $-1.1 \mathrm{~m} / \mathrm{s}^{2}$ \\
\hline$L_{s}$ & $5 \mathrm{mH}$ & $g\left(m / s^{2}\right)$ & 9.81 \\
\hline$R_{S}$ & $10 \mathrm{~m} \Omega$ & $r_{\text {wheel }}$ & $0.42 m$ \\
\hline$C_{\text {Filter }}$ & $1000 \mu F$ & $K_{\text {rolling }}$ & 0.0024 \\
\hline$R_{E S R}$ & $1.3 \mathrm{~m} \Omega$ & $\rho\left(\mathrm{kg} / \mathrm{m}^{3}\right)$ & 1.23 \\
\hline$L_{\text {Filter }}$ & $7 \mathrm{mH}$ & $C_{d} A_{f}$ & $7.2 \mathrm{~m}^{2}$ \\
\hline$L_{c}$ & $10.2 m H$ & $\theta_{\text {slope }}$ & 0 degree \\
\hline$C_{c}$ & $100 \mu F$ & $N_{1}$ and $N_{1}^{\prime}$ & 2 \\
\hline$f_{T M C S}$ & $1 \mathrm{kHz}$ & $N_{2}$ and $N_{2}^{\prime}$ & 1 \\
\hline$f_{\text {system }}$ & $50 \mathrm{~Hz}$ & $\sigma_{1}^{\prime}, \sigma_{2}, \sigma_{2}^{\prime}$ & 0.5 \\
\hline$f_{S, S B A S}$ & $5 \mathrm{kHz}$ & $\sigma_{1}$ & 0.6 \\
\hline Coach weight & $46300 \mathrm{~kg}$ & $\gamma$ & 1.2 \\
\hline Coaches No. & 6 & & \\
\hline
\end{tabular}

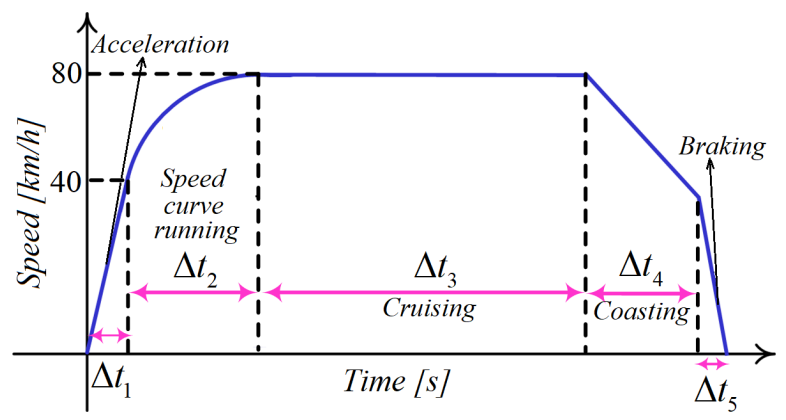

Fig. 6. Considered drive cycle for testing the proposed SBAS in scenario A.

Different scenarios are simulated to assess the performance of the proposed method, which are discussed in Sections IV-A and IV-B.

\section{A. Performance of the Proposed Method in Reducing the DC-Link Voltage Variations}

In this scenario, the drive cycle of Fig. 6 is considered in the simulations. The train starts from the standstill condition with a constant acceleration of $1.2 \mathrm{~m} / \mathrm{s}^{2}$. After $\Delta t_{1}=9.3 \mathrm{~s}$, the train reaches the base speed of $40 \mathrm{~km} / \mathrm{h}$. Then, the speed curve running mode is activated for $\Delta t_{2}=15 \mathrm{~s}$, during which the speed of the train increases at a lower rate. When the train reaches its top speed of $80 \mathrm{~km} / \mathrm{h}$, it cruises for $\Delta t_{3}=54 \mathrm{~s}$, which then follows by coasting and braking (deceleration) events for $\Delta t_{4}=15 \mathrm{~s}$ and $\Delta t_{5}=10.1 \mathrm{~s}$, respectively. The deceleration of the train to a standstill condition is fulfilled with a constant negative deceleration of $-1.1 \mathrm{~m} / \mathrm{s}^{2}$. The results of scenario A without and with utilizing the proposed SBAS are shown in Figs. 7 and 8, respectively.

Fig. 7(a) shows the simulated and reference speed of the train. The reference speed is generated based on the drive cycle described in Fig. 6. In Fig. 7(b), the net tractive force of the simulated train is shown. It is evident that during the acceleration phase $\left(\Delta t_{1}\right)$, the train demands a very high constant torque. As the train enters the speed curve running mode $\left(\Delta t_{2}\right)$, the required tractive force decreases gradually.
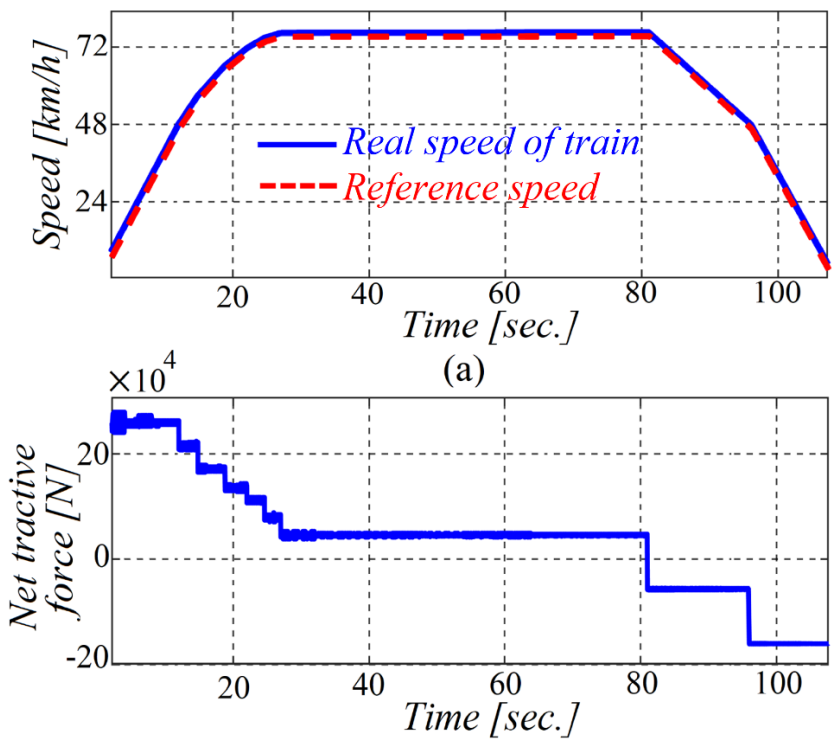

(b)

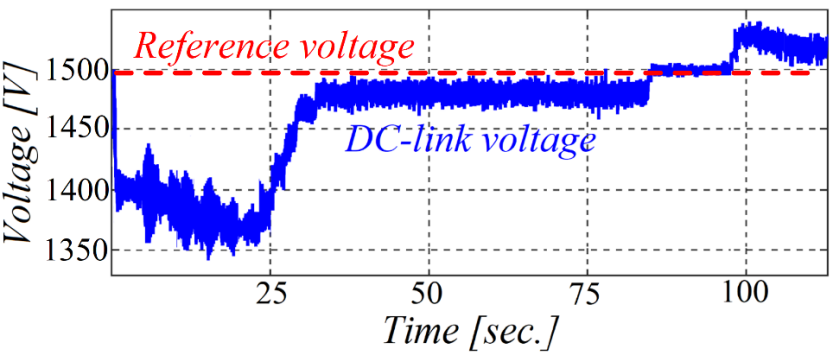

(c)

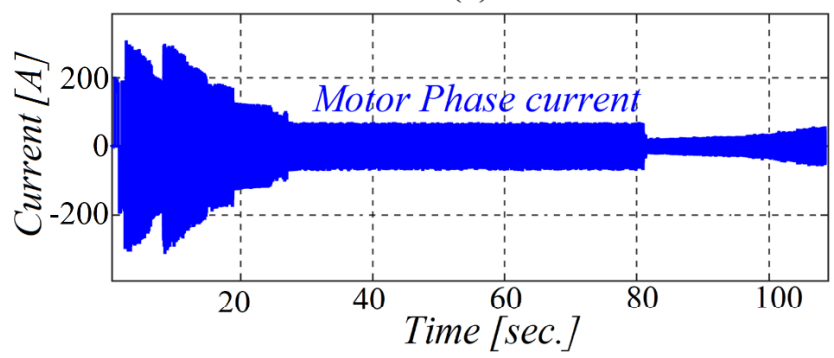

(d)

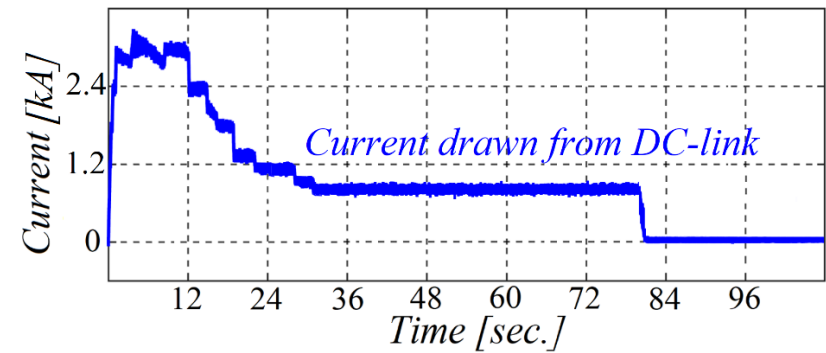

(e)

Fig. 7. Simulation results of scenario A without utilizing the SBAS (a) Reference drive cycle speed and simulated train speed. (b) Net tractive force of the whole train. (c) DC-link voltage and its reference value. (d) Phase A current of one traction motor. (e) Current taken from the dc-link by the train.

In addition, when the train slows down after $t=80 \mathrm{~s}$, the tractive force becomes negative due to the deceleration of the train. As seen in Fig. 7(c), during the train acceleration, the dc-link voltage drops to about $1350 \mathrm{~V}$ due to the large tractive force of the train. However, the dc-link voltage increases 


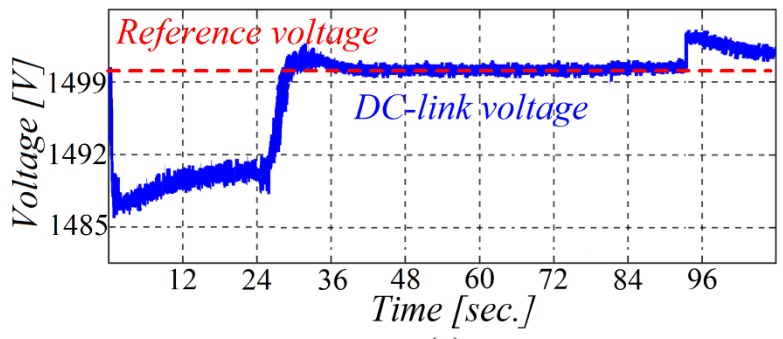

(a)

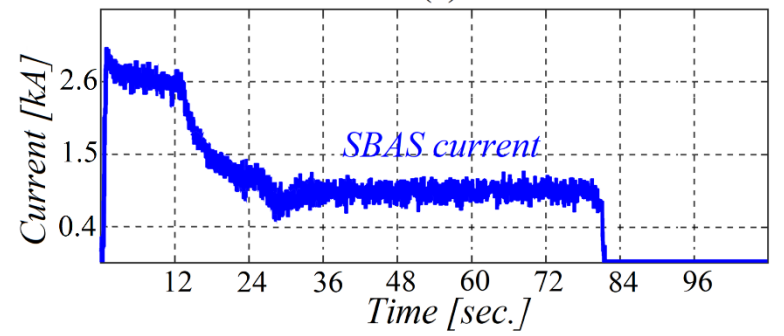

(b)

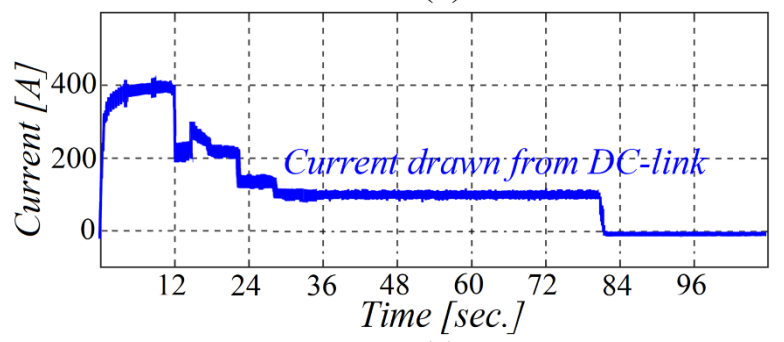

(c)

Fig. 8. Simulation results of scenario A with utilization of the proposed SBAS. (a) DC-link voltage and its reference value. (b) SBAS current ( $i_{\text {SBAS }}$ ). (c) Current taken from the dc-link by the vehicle.

to about $1475 \mathrm{~V}$ when the train reaches its top speed and continues cruising to the destination. Fig. 7(d) and (e) shows the motor phase current and the dc-link current, respectively. It is evident that during the acceleration of the train, a large inrush current is drawn from the dc-link by the traction motor, which causes large variations in the dc-link voltage. At $t=80 \mathrm{~s}$, the train slows down (coasting and braking phases) and comes to a standstill at the end station. The braking event which is fulfilled by braking the chopper causes dc-link overvoltage between $t=96 \mathrm{~s}$ and $t=108 \mathrm{~s}$. The general assessment is that the dc-link voltage experiences a voltage drop from $1500 \mathrm{~V}$ to about $1350-\mathrm{V}$ dc. Such large variations of the dc-link voltage are undesirable as they increase the electrical stress and power losses of the system components. In the worst case, such voltage drops might lead to instability of the dc-link. The simulation results when the proposed SBAS with TMCS is utilized are shown in Fig. 8. As is seen, the voltage drop does not exceed $1 \%$ when the proposed SBAS is used. The SBAS works in the primary control mode between $t=0$ and $t=26.6 \mathrm{~s}$. After $t=26.6 \mathrm{~s}$, the TMCS successfully switches to mode 2 to tightly regulate the dc-link voltage.

\section{B. Performance of the Proposed Method in Improving the DC-Link Voltage Stability When a Disturbance Occurs on the AC Grid}

As discussed before, the disturbances on the ac grid such as momentary voltage drops, voltage sags, or even fault

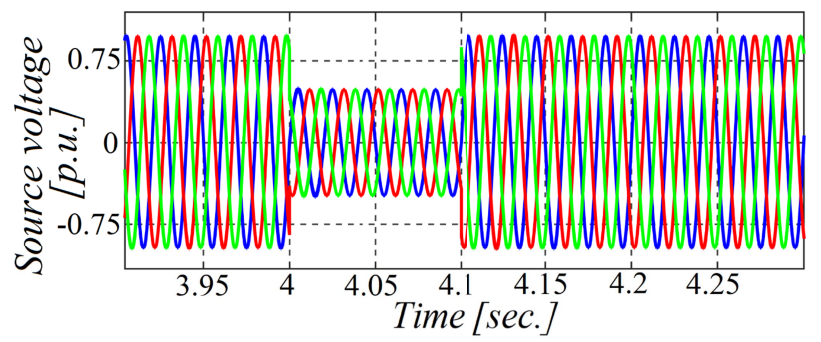

(a)

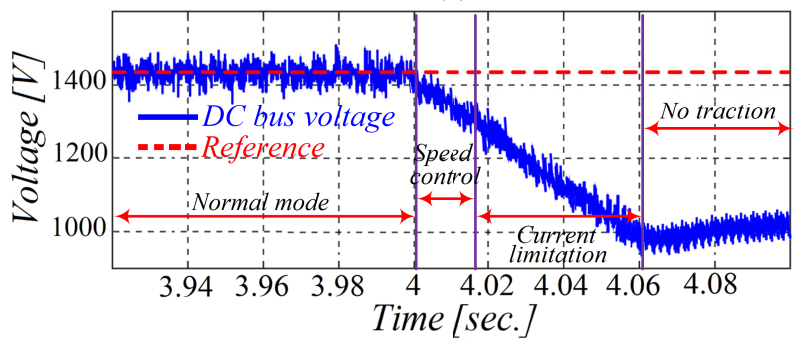

(b)

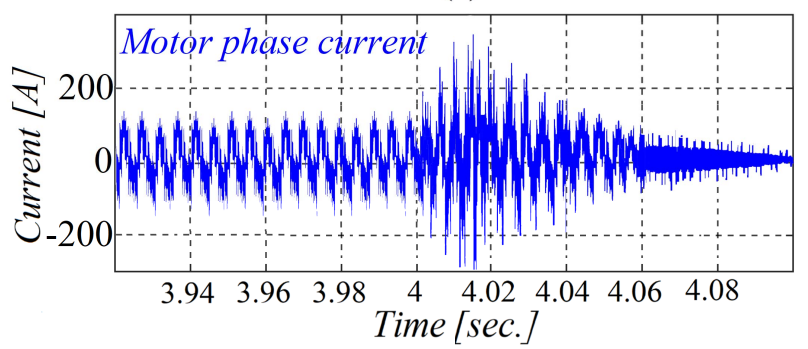

(c)

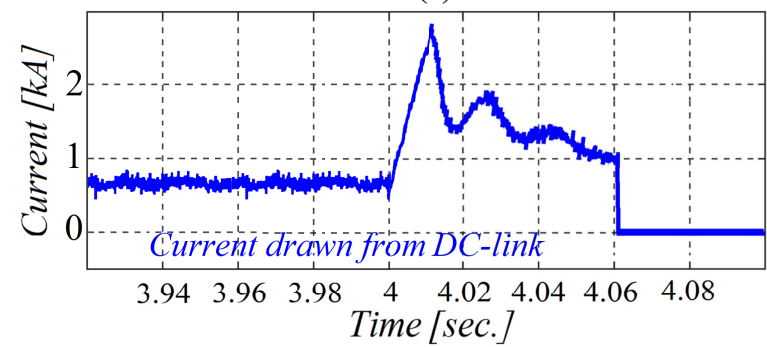

(d)

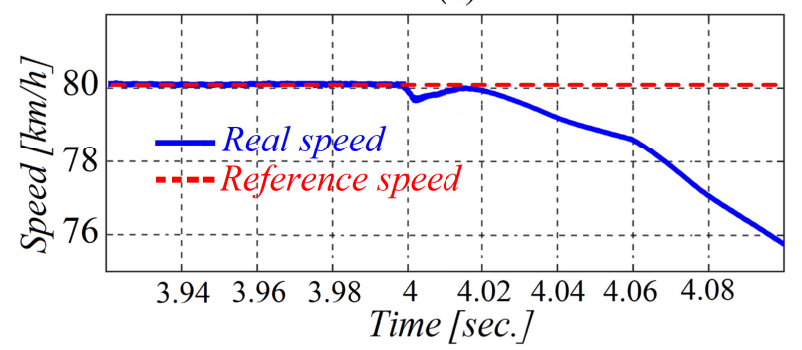

(e)

Fig. 9. Simulation results of scenario B without utilizing the proposed SBAS. (a) Three-phase source voltage. (b) DC-link voltage. (c) Phase A current of the motor. (d) Current drawn from the dc-link by the vehicle. (e) Real and reference train speeds.

conditions can lead to instability of the de traction system, which contains cascaded converters. Fig. 9 shows the simulation results of the system when a voltage sag condition with a depth of 0.5 p.u. occurs at the upstream ac grid. It is assumed that the sag condition occurs when the train is cruising at $80 \mathrm{~km} / \mathrm{h}$. As is seen, the system operates in a stable condition before the voltage sag occurs at $t=4 \mathrm{~s}$. Upon the voltage sag occurrence, the dc-link voltage experiences a monotonous 


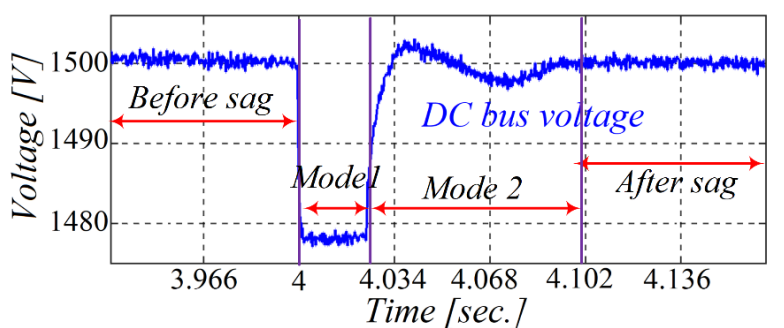

(a)

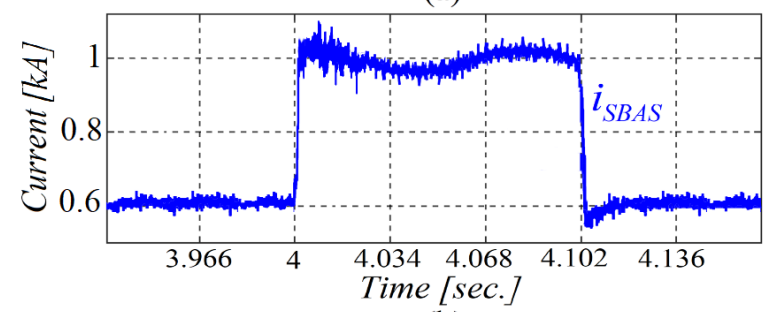

(b)

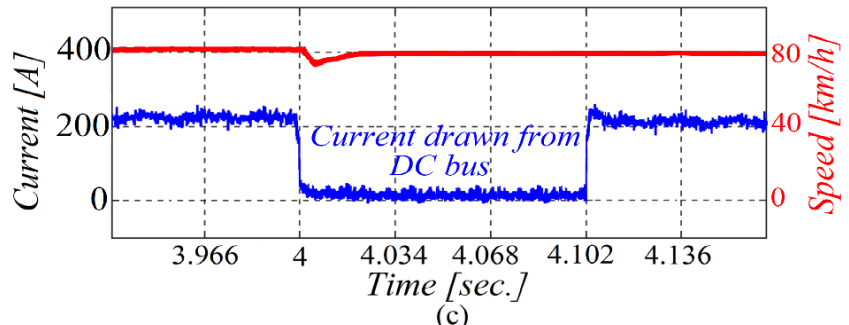

(c)

Fig. 10. Simulation results of scenario B with utilizing the proposed SBAS (a) DC-link voltage. (b) SBAS current. (c) Current drawn from the dc-link and the train speed.

decrease. As the dc-link voltage decreases between $t=4 \mathrm{~s}$ and $t=4.016 \mathrm{~s}$, since the closed-loop traction converter acts as a CPL, it tries to maintain the train speed by drawing more current from the dc-link, which aggravates the divergence from the rated operating point. At $t=4.016 \mathrm{~s}$, the dc-link voltage drops below $1350 \mathrm{~V}$, and thus the automatic regulation (based on EN 50388) is activated to maintain the dc-link stability by reducing the power consumption of the train. Under such circumstances, as seen in Fig. 9(e), the train is forced to operate at reduced speeds. However, since the dc-link cannot be supplied by the power source during the voltage sag conditions, the dc-link voltage continues to decrease until $t=4.06 \mathrm{~s}$, when it reaches the minimum long-term voltage limit of 1000-V dc (based on EN 50163). Afterward, the traction units are totally deactivated. Thus, despite the involvement of the current limitation scheme, it is still probable that the dc-link voltage collapses when momentary disturbances occur on the grid side. The simulation results of the dc traction system in the presence of the proposed SBAS under the same voltage sag conditions are shown in Fig. 10. As seen in Fig. 10, when the proposed SBAS is used, the dc-link voltage never drops below $\sim 98 \%$ of the rated dc-link voltage. Before the voltage sag occurrence at $t=4 \mathrm{~s}$, the SBAS works in the second control mode to compensate for the resistive voltage drop across the feeder. When the voltage sag condition begins, the SBAS switches to the first control mode and rapidly restrains the dc-link voltage by fast current injection. From $t=4 \mathrm{~s}$ to $t=4.026 \mathrm{~s}$, the SBAS is controlled in the primary control mode. The TMCS switches to mode 2 at $t=4.026 \mathrm{~s}$

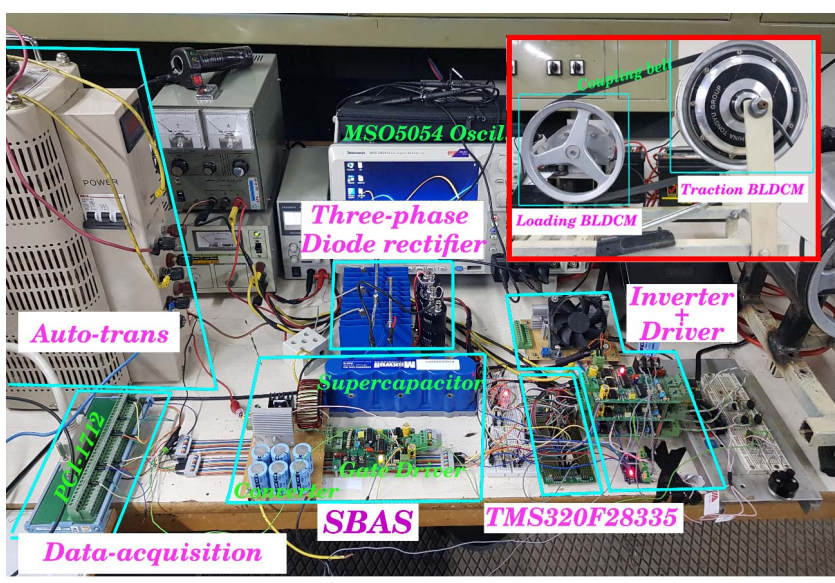

Fig. 11. Implemented test bench.

TABLE II

PARAMETERS OF THE SCALEd Prototype

\begin{tabular}{cc}
\hline \hline Parameter & value \\
\hline Traction PMSM & $1.5 \mathrm{~kW}, 72 \mathrm{~V}$ \\
Loading PMSM & $1.2 \mathrm{~kW}, 48 \mathrm{~V}$ \\
$\mu-$ processor & TMS320F 28335 \\
Current sensors & ACS712 \\
Supercapacitor & Maxwell $16 \mathrm{~V}$ module \\
$L_{s}$ & $30 \mathrm{mH}$ \\
$R_{s}$ & $1.2 \Omega$ \\
$C_{\text {Filter }}$ & $1000 \mu \mathrm{F}$ \\
$L_{\text {Filter }}$ & $7 \mathrm{mH}$ \\
$L_{c}$ & $10.2 \mathrm{mH}$ \\
$C_{c}$ & $100 \mu F$ \\
$f_{T M C S}$ & $1 \mathrm{kHz}$ \\
$f_{\text {system }}$ & $50 \mathrm{~Hz}$ \\
$f_{S, S B A S}$ & $5 \mathrm{kHz}$ \\
Gate drivers & $\mathrm{IR} 2113 \mathrm{ICs}$ \\
Optocouplers & $4 \mathrm{~N} 28$ \\
Data-acquisition card & $\mathrm{PCI} 1711$ \\
\hline
\end{tabular}

to accurately recover the dc-link voltage to its reference value, by working in the secondary voltage-controlled mode. As seen in Fig. 10(c), the train speed tends to decrease upon initiation of voltage sag conditions. However, the train suddenly recovers its rated speed with the aid of the proposed SBAS. Thus, the proposed SBAS effectively maintains the dc-link stability, which in turn guarantees the safe and continuous flow of rail traffic.

To confirm the simulation results and to assess the real-time feasibility of the proposed MPC-based TMCS, a series of HIL experiments are conducted. Fig. 11 shows the implemented test bench for the HIL experiments. The three-phase, 380-V $\mathrm{LV}$ grid ac voltage is converted to $72-\mathrm{V}$ dc (rated voltage of the considered traction motor) using a three-phase autotransformer and a three-phase full-bridge diode rectifier to effectively emulate the subway dc substation. A resistor is inserted between the dc bus of the diode rectifier and the dc-link of the traction inverter to emulate the voltage drop on the dc feeders of the subway system. A 72-V permanent magnet synchronous motor (PMSM) with $1.5-\mathrm{kW}$ power is considered as the traction motor. The traction inverter is tightly controlled in the closed-loop speed control mode using the PWM technique to effectively mimic the CPL behavior [16]. 


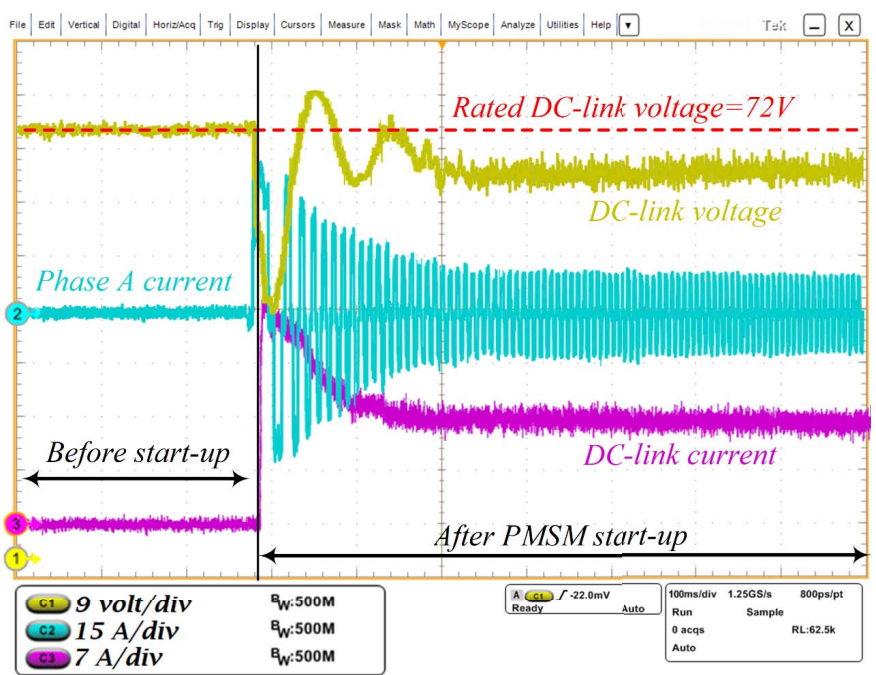

(a)

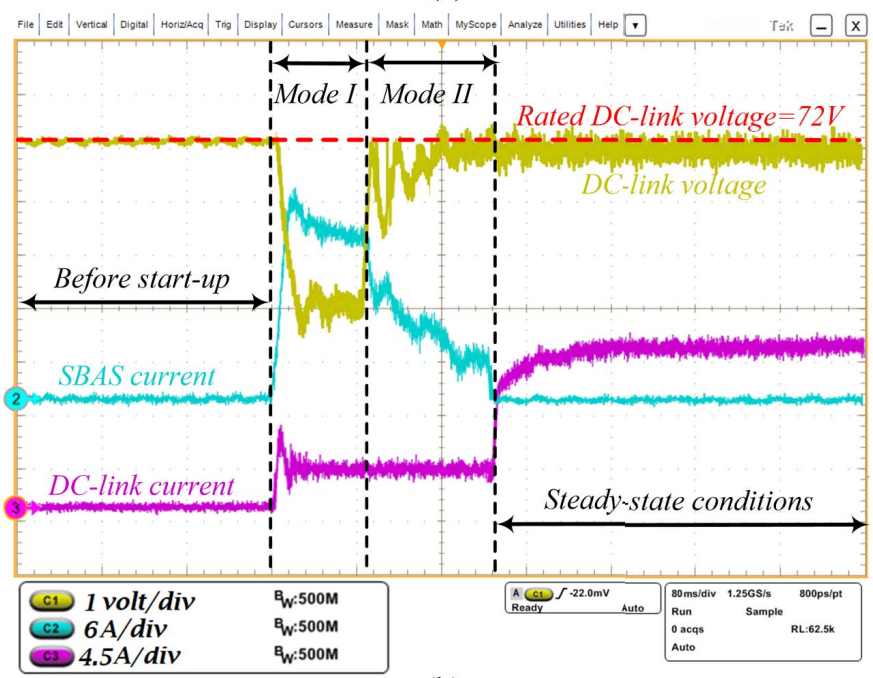

(b)

Fig. 12. Experimental results with and without utilizing the proposed SBAS when the traction PMSM starts from standstill under a heavy load. (a) Without the proposed SBAS. (b) With the proposed SBAS.

In order to emulate the overall loading of the subway coach, a second 1.2-kW PMSM is coupled with the traction PMSM using a coupling belt. The mechanical loading of the traction PMSM is regulated by changing the electrical load of the second PMSM. A scaled-down SBAS is also fabricated and connected to the dc-link of the traction inverter. The SBAS is equipped with two series-connected $16 \mathrm{~V}, 56-\mathrm{F}$, supercapacitor modules from Maxwell Technologies. The whole control algorithm including the TMCS, switching algorithm of the MOSFETs, speed controller, etc. is implemented on DSP TMS320F28335 from Texas Instruments. Detailed experimental parameters are tabulated in Table II. The performance of the proposed SBAS is experimentally assessed under a typical start-up event of the PMSM. This scenario emulates the startup of the traction motor of the subway coach from standstill conditions under heavy load. The experimental results without utilizing the proposed SBAS are shown in Fig. 12(a). As seen in Fig. 12(a), when the traction PMSM started without the proposed SBAS, due to the heavy inrush current of the PMSM, a large current is drawn from the dc-link, which causes the dc-link voltage drops from the rated value of $72 \mathrm{~V}$ to about $50 \mathrm{~V}$. As seen in Fig. 12(b), when the proposed SBAS is utilized, the dc-link voltage drop is significantly reduced to $\sim 3 \mathrm{~V}$. The primary control mode (Mode I) first stabilizes the dc-link voltage by sudden injection of current to the dc-link. Upon satisfaction of the stabilization criterion, the SBAS starts to work in the secondary control mode (Mode II) to tightly regulate the dc-link voltage. In the steady-state, when the motor start-up time-interval is finished, the SBAS current is set to zero and the dc-link voltage is recovered to its initial value. Therefore, it is evident that the proposed SBAS with TMCS can effectively mitigate the level of voltage drop in the emulated dc traction system.

\section{CONCLusion ANd Future Work}

In this article, an effective SBAS with MPC-based TMCS is proposed for dc-link voltage stabilization in dc traction systems. When a destabilizing disturbance occurs, the proposed method fulfills the objectives of: 1) maintaining the dc-link voltage stability and 2) regulating the dc-link voltage using the proposed TMCS. In the first mode, the SBAS works in the current-controlled mode to represent adaptive capacitance behavior for dc-link voltage stabilization. In the second mode, the SBAS operates in the voltage-controlled mode to tightly regulate the dc-link voltage. The effectiveness of the proposed approach is demonstrated using several simulations and experiments. It is deduced that with the proposed method not only the stability of the dc-link is assured, but also the maximum depth of voltage drop does not increase by $2 \%$ in the worst case.

For future work, it is worthwhile to evaluate the performance of the proposed method when a fault in the upstream ac grid occurs. As usual, a tradeoff between the overall system cost and performance should be made; future work can also focus on optimizing the SBAS design according to the foregoing two constraints.

\section{APPENDiX A}

The CPL is approximated by a negative resistance in parallel with a current source as follows:

$$
R_{\mathrm{CPL}}=-\frac{V_{\mathrm{CPL}}^{2}}{P_{\mathrm{CPL}}}, \quad I_{\mathrm{CPL}}=\frac{2 P_{\mathrm{CPL}}}{V_{\mathrm{CPL}}} .
$$

\section{APPENDIX B}

In order to obtain the $j$-step ahead prediction of $I_{\text {SBAS }}(k)$ $\left(\hat{I}_{\mathrm{SBAS}}(k+j)\right)$, the Diophantine equation of (15) should be solved. In (15), $\tilde{A}\left(z^{-1}\right)$ is obtained as follows:

$$
\begin{aligned}
\tilde{A}\left(z^{-1}\right) & =\Delta A\left(z^{-1}\right)=\left(1-z^{-1}\right)\left(K_{1}-K_{2} z^{-1}-K_{3} z^{-2}\right) \\
& =K_{1}-\left(K_{1}+K_{2}\right) z^{-1}+\left(K_{2}-K_{3}\right) z^{-2}+K_{3} z^{-3} .
\end{aligned}
$$




$$
\begin{aligned}
\frac{1}{\tilde{A}\left(z^{-1}\right)}= & \underbrace{\frac{1}{K_{1}}+\left(\frac{K_{1}+K_{2}}{K_{1}^{2}}\right) z^{-1}}_{E_{2}\left(z^{-1}\right)} \\
& +\frac{\left.z^{-2}\left(\frac{K_{2}\left(z^{-1}\right)}{K_{1} K_{2}}\right)^{2}-\frac{K_{2}-K_{3}}{K_{1}}-\left(\frac{\left(K_{1}+K_{2}\right)\left(K_{2}-K_{3}\right)}{K_{1}^{2}}+\frac{K_{3}}{K_{1}}\right) z^{-1}-\frac{K_{3}\left(K_{1}+K_{2}\right)}{K_{1}^{2}} z^{-2}\right)}{\tilde{A}\left(z^{-1}\right)} .
\end{aligned}
$$

For one-step ahead prediction, the z-polynomials $E_{1}\left(z^{-1}\right)$ and $F_{1}\left(z^{-1}\right)$ are obtained by solving the Diophantine equation for $j=1$ as follows:

$$
\frac{1}{\tilde{A}\left(z^{-1}\right)}=\underbrace{\frac{1}{K_{1}}}_{E_{1}\left(z^{-1}\right)}+\frac{z^{-1} \overbrace{\left(\frac{K_{1}+K_{2}}{K_{1}}-\frac{K_{2}-K_{3}}{K_{1}} z^{-1}-\frac{K_{3}}{K_{1}} z^{-2}\right)}^{F_{1}\left(z^{-1}\right)}}{\tilde{A}\left(z^{-1}\right)}
$$

Using (17) and the obtained polynomials $E_{1}\left(z^{-1}\right)$ and $F_{1}\left(z^{-1}\right)$, the one-step ahead prediction $\hat{I}_{\mathrm{SBAS}}(k+1)$ of $(19)$ can be easily obtained. For the two-step ahead prediction, the $z$ polynomials $E_{2}\left(z^{-1}\right)$ and $F_{2}\left(z^{-1}\right)$ are obtained as in (B.3).

\section{REFERENCES}

[1] R. Hou, Y. Yang, and A. Emadi, "Hybrid electric locomotive powertrains," in Proc. IEEE Conf. Expo Transp. Electrific. Asia-Pacific (ITEC Asia-Pacific), Aug. 2014, pp. 1-6.

[2] A. Rufer, D. Hotellier, and P. Barrade, "A supercapacitor-based energy storage substation for voltage compensation in weak transportation networks," IEEE Trans. Power Del., vol. 19, no. 2, pp. 629-636, Apr. 2004.

[3] A. Emadi, A. Khaligh, C. Rivetta, and G. Williamson, "Constant power loads and negative impedance instability in automotive systems: Definition, modeling, stability, and control of power electronic converters and motor drives," IEEE Trans. Veh. Technol., vol. 55, no. 4, pp. 1112-1125, Jul. 2006.

[4] T. Ghanbari, E. Farjah, and F. Naseri, "Power quality improvement of radial feeders using an efficient method," Electr. Power Syst. Res., vol. 163, pp. 140-153, Oct. 2018.

[5] F. Naseri and H. Samet, "A comparison study of high power IGBTbased and thyristor-based AC to DC converters in medium power DC arc furnace plants," in Proc. 9th Int. Conf. Compat. Power Electron. (CPE), Jun. 2015, pp. 14-19.

[6] F. Ciccarelli, D. Iannuzzi, and P. Tricoli, "Control of metro-trains equipped with onboard supercapacitors for energy saving and reduction of power peak demand," Transp. Res. C, Emerg. Technol., vol. 24, pp. 36-49, Oct. 2012.

[7] F. Ciccarelli, D. Iannuzzi, K. Kondo, and L. Fratelli, "Line-voltage control based on wayside energy storage systems for tramway networks," IEEE Trans. Power Electron., vol. 31, no. 1, pp. 884-899, Jan. 2016.

[8] A.-L. Allegre, A. Bouscayrol, P. Delarue, P. Barrade, E. Chattot, and S. El-Fassi, "Energy storage system with supercapacitor for an innovative subway," IEEE Trans. Ind. Electron., vol. 57, no. 12, pp. 4001-4012, Dec. 2010.

[9] A. Bouscayrol, W. Lhomme, C. Demian, A. L. Allegre, E. Chattot, and S. El Fassi, "Experimental set-up to test the power transfer of an innovative subway using supercapacitors," in Proc. IEEE Vehicle Power Propuls. Conf., Sep. 2010, pp. 1-6.

[10] D. Iannuzzi, F. Ciccarelli, and D. Lauria, "Stationary ultracapacitors storage device for improving energy saving and voltage profile of light transportation networks," Transp. Res. C, Emerg. Technol., vol. 21, no. 1, pp. 321-337, Apr. 2012.
[11] H. Xia, H. Chen, Z. Yang, F. Lin, and B. Wang, "Optimal energy management, location and size for stationary energy storage system in a metro line based on genetic algorithm," Energies, vol. 8, no. 10, pp. 11618-11640, Oct. 2015.

[12] X. Zhang, "Impedance control and stability of DC/DC converter systems," Ph.D. dissertation, Dept. Eng., Univ. Sheffield, Sheffield, England, 2016.

[13] A. Rahimi and A. Emadi, "Active damping in DC/DC power electronic converters: A novel method to overcome the problems of constant power loads," IEEE Trans. Ind. Electron., vol. 56, no. 5, pp. 1428-1439, May 2009.

[14] A. Rahimi, G. Williamson, and A. Emadi, "Loop-cancellation technique: A novel nonlinear feedback to overcome the destabilizing effect of constant-power loads," IEEE Trans. Veh. Technol., vol. 59, no. 2, pp. 650-661, Feb. 2010.

[15] X. Zhang, D. M. Vilathgamuwa, K.-J. Tseng, B. S. Bhangu, and C. J. Gajanayake, "Power buffer with model predictive control for stability of vehicular power systems with constant power loads," IEEE Trans. Power Electron., vol. 28, no. 12, pp. 5804-5812, Dec. 2013.

[16] F. Naseri, E. Farjah, and T. Ghanbari, "An efficient regenerative braking system based on battery/supercapacitor for electric, hybrid, and plug-in hybrid electric vehicles with BLDC motor," IEEE Trans. Veh. Technol., vol. 66, no. 5, pp. 3724-3738, May 2017.

[17] F. Naseri, E. Farjah, M. Allahbakhshi, and Z. Kazemi, "Online condition monitoring and fault detection of large supercapacitor banks in electric vehicle applications," IET Electr. Syst. Transp., vol. 7, no. 4, pp. 318-326, Dec. 2017.

[18] J. Shen and A. Khaligh, "A supervisory energy management control strategy in a battery/ultracapacitor hybrid energy storage system," IEEE Trans. Transport. Electrific., vol. 1, no. 3, pp. 223-231, Oct. 2015.

[19] S. Farag, C. Lerman, S. Lineykin, and A. Kuperman, "Off-the-shelf power supply-based battery/supercapacitor emulator for charger functionality testing," IEEE Trans. Transport. Electrific., vol. 2, no. 2, pp. 129-139, Jun. 2016.

[20] E. Schaltz, A. Khaligh, and P. Rasmussen, "Influence of battery/ultracapacitor energy-storage sizing on battery lifetime in a fuel cell hybrid electric vehicle," IEEE Trans. Veh. Technol., vol. 58, no. 8, pp. 3882-3891, Oct. 2009.

[21] A.-A. Mamun, Z. Liu, D. M. Rizzo, and S. Onori, "An integrated design and control optimization framework for hybrid military vehicle using lithium-ion battery and supercapacitor as energy storage devices," IEEE Trans. Transport. Electrific., vol. 5, no. 1, pp. 239-251, Mar. 2019.

[22] E. F. Camacho and C. B. Alba, Model Predictive Control. London, U.K.: Springer, pp. 53-58, 2007.

[23] P. Cortes et al., "Guidelines for weighting factors design in model predictive control of power converters and drives," in Proc. IEEE Int. Conf. Ind. Technol., Feb. 2009, pp. 1-7.

[24] A. Emadi, Handbook of Automotive Power Electronics and Motor Drives. Boca Raton, FL, USA: CRC Press, 2017.

[25] A. Emadi, Advanced Electric Drive Vehicles. Boca Raton, FL, USA: CRC Press, 2014.

[26] A. K. Chauhan and S. K. Singh, "Integrated dual-output L-Z source inverter for hybrid electric vehicle," IEEE Trans. Transport. Electrific., vol. 4, no. 3, pp. 732-743, Sep. 2018.

[27] F. Naseri, E. Farjah, T. Ghanbari, Z. Kazemi, E. Schaltz, and J. L. Schanen, "Online parameter estimation for supercapacitor stateof-energy and state-of-health determination in vehicular applications," IEEE Trans. Ind. Electron., early access, 2019, doi: 10.1109/TIE. 2019.2941151. 